\title{
Internal versus external tocodynamometry during induced or augmented labour (Review)
}

Bakker JJH, Janssen PF, van Halem K, van der Goes BY, Papatsonis DN, van der Post JAM, Mol BWJ
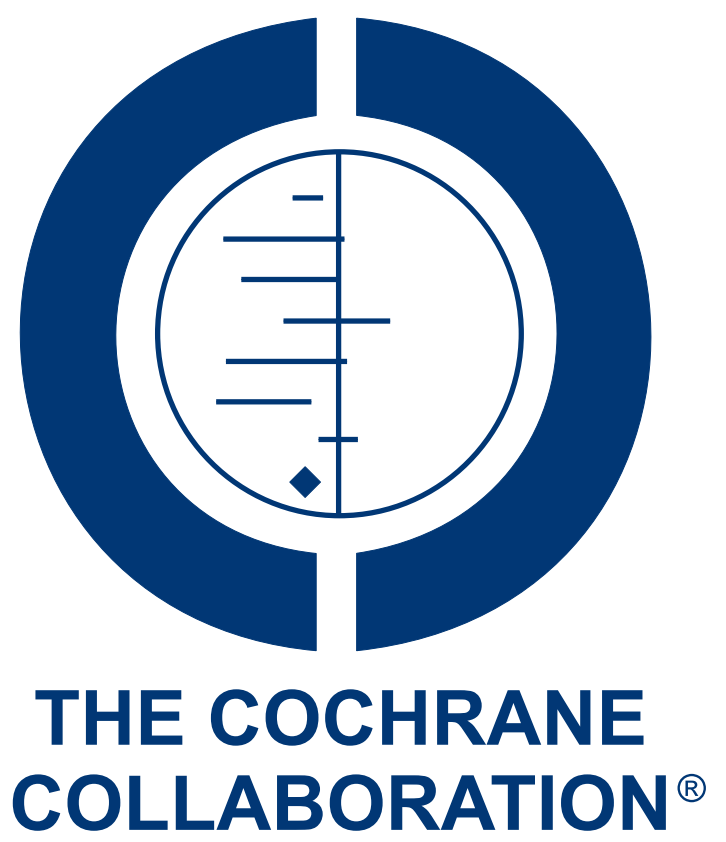

This is a reprint of a Cochrane review, prepared and maintained by The Cochrane Collaboration and published in The Cochrane Library 2012, Issue 12

http://www.thecochranelibrary.com

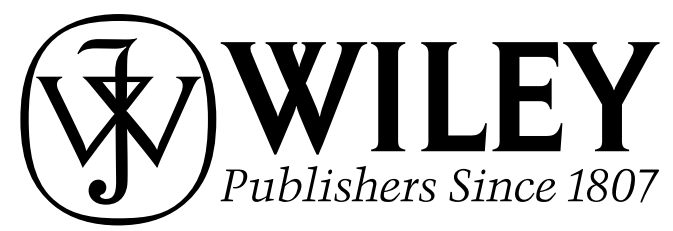

Internal versus external tocodynamometry during induced or augmented labour (Review)

Copyright $\odot 2012$ The Cochrane Collaboration. Published by John Wiley \& Sons, Ltd. 
TABLE OF CONTENTS

HEADER . . . . . . . . . . . . . . . . . . . . . . . . . . . . . . . . . . . . . . . . . . . . . . . . . . . .

ABSTRACT . . . . . . . . . . . . . . . . . . . . . . . . . . . . . . . . . . . . . . . . . . . . . . . . . . . . . . .

PLAIN LANGUAGE SUMMARY . . . . . . . . . . . . . . . . . . . . . . . . . . . . . . . . . . . . . . . . . . . . .

SUMMARY OF FINDINGS FOR THE MAIN COMPARISON . . . . . . . . . . . . . . . . . . . . . . . . . . . . 2

BACKGROUND . . . . . . . . . . . . . . . . . . . . . . . . . . . . . . . . . . . . . . . . . . . . 6

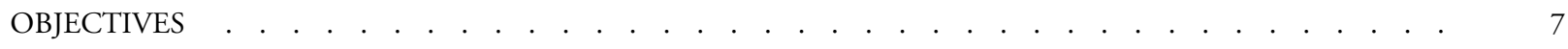

METHODS . . . . . . . . . . . . . . . . . . . . . . . . . . . . . . . . . . . . . . . . . . . .

RESULTS . . . . . . . . . . . . . . . . . . . . . . . . . . . . . . . . . . . . . . . . .

DISCUSSION . . . . . . . . . . . . . . . . . . . . . . . . . . . . . . . . . . . . . . . . . . . . . .

AUTHORS' CONCLUSIONS . . . . . . . . . . . . . . . . . . . . . . . . . . . . . . . . . . . . . .

ACKNOWLEDGEMENTS . . . . . . . . . . . . . . . . . . . . . . . . . . . . . . . . . . . . . . . . . . . . .

REFERENCES . . . . . . . . . . . . . . . . . . . . . . . . . . . . . . . . . . . . . . . . . . . . . . .

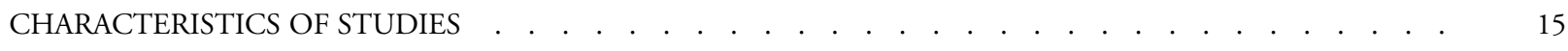

DATA AND ANALYSES . . . . . . . . . . . . . . . . . . . . . . . . . . . . . . . . . . . . . . . . . . . . . . . . . . .

Analysis 1.1. Comparison 1 Monitoring of contractions with internal tocodynamometry compared to external

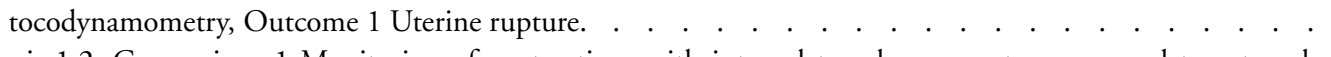

Analysis 1.2. Comparison 1 Monitoring of contractions with internal tocodynamometry compared to external tocodynamometry, Outcome 2 Hyperstimulation. . . . . . . . . . . . . . . . . . . . . . . . .

Analysis 1.3. Comparison 1 Monitoring of contractions with internal tocodynamometry compared to external tocodynamometry, Outcome 3 Apgar score less than seven at five minutes. . . . . . . . . . . . . . . . . .

Analysis 1.4. Comparison 1 Monitoring of contractions with internal tocodynamometry compared to external tocodynamometry, Outcome 4 Umbilical artery $\mathrm{pH}<7.15$. . . . . . . . . . . . . . . . . . . . . .

Analysis 1.5. Comparison 1 Monitoring of contractions with internal tocodynamometry compared to external tocodynamometry, Outcome 5 Umbilical artery $\mathrm{pH}<7.05$. . . . . . . . . . . . . . . . . . . . . . .

Analysis 1.6. Comparison 1 Monitoring of contractions with internal tocodynamometry compared to external tocodynamometry, Outcome 6 Umbilical artery $\mathrm{pH}<7.16$. . . . . . . . . . . . . . . . . . . . . .

Analysis 1.7. Comparison 1 Monitoring of contractions with internal tocodynamometry compared to external tocodynamometry, Outcome 7 Admission to neonatal intensive care. . . . . . . . . . . . . . . . . . . .

Analysis 1.8. Comparison 1 Monitoring of contractions with internal tocodynamometry compared to external tocodynamometry, Outcome 8 Neonatal admission $>48$ hours. $\quad . \quad$. . . . . . . . . . . . . . . . . . . . .

Analysis 1.9. Comparison 1 Monitoring of contractions with internal tocodynamometry compared to external tocodynamometry, Outcome 9 Perinatal mortality. . . . . . . . . . . . . . . . . . . . . . . . . . . . . . .

Analysis 1.10. Comparison 1 Monitoring of contractions with internal tocodynamometry compared to external tocodynamometry, Outcome 10 Serious maternal outcomes (defined as death, coma, cardiac arrest, respiratory arrest, use of a mechanical ventilator, admission to intensive care unit). $\quad . \quad$. . . . . . . . . . . . . . . . . . . . .

Analysis 1.11. Comparison 1 Monitoring of contractions with internal tocodynamometry compared to external tocodynamometry, Outcome 11 Instrumental delivery. . . . . . . . . . . . . . . . . . . . .

Analysis 1.12. Comparison 1 Monitoring of contractions with internal tocodynamometry compared to external tocodynamometry, Outcome 12 Instrumental vaginal delivery. . . . . . . . . . . . . . . . . . . . . .

Analysis 1.13. Comparison 1 Monitoring of contractions with internal tocodynamometry compared to external tocodynamometry, Outcome 13 Caesarean section. . . . . . . . . . . . . . . . . . . . . . . . . . . . . . .

Analysis 1.14. Comparison 1 Monitoring of contractions with internal tocodynamometry compared to external tocodynamometry, Outcome 14 Mean time to delivery. . . . . . . . . . . . . . . . . . . . . . . . . .

Analysis 1.15. Comparison 1 Monitoring of contractions with internal tocodynamometry compared to external tocodynamometry, Outcome 15 Placental or fetal vessel damage. . . . . . . . . . . . . . . . . . . . . . .

Analysis 1.16. Comparison 1 Monitoring of contractions with internal tocodynamometry compared to external tocodynamometry, Outcome 16 Indication of infection up to three weeks postpartum in mother or child. .

Analysis 1.17 . Comparison 1 Monitoring of contractions with internal tocodynamometry compared to external tocodynamometry, Outcome 17 Signs intrauterine infection during labor. . . . . . . . . . . . . . . .

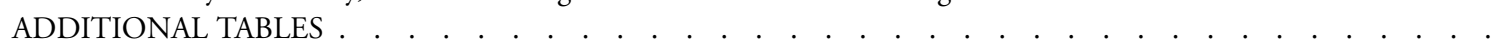

APPENDICES . . . . . . . . . . . . . . . . . . . . . . . . . . . . . . . . . . . . . . . . . . . . . . . . .

Internal versus external tocodynamometry during induced or augmented labour (Review)

Copyright @ 2012 The Cochrane Collaboration. Published by John Wiley \& Sons, Ltd. 
HISTORY . . . . . . . . . . . . . . . . . . . . . . . . . . . . . . . . . . . . . . . . . . . . .

CONTRIBUTIONS OF AUTHORS . . . . . . . . . . . . . . . . . . . . . . . . . . . . . . . . . . . . . . . . . .

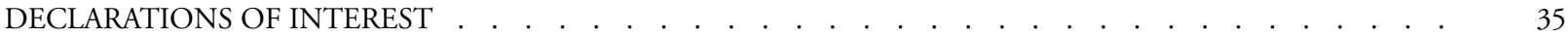

SOURCES OF SUPPORT . . . . . . . . . . . . . . . . . . . . . . . . . . . . . . . . . . . . . . . . . . . . . . .

DIFFERENCES BETWEEN PROTOCOL AND REVIEW . . . . . . . . . . . . . . . . . . . . . . . . . . . . . . .

INDEX TERMS . . . . . . . . . . . . . . . . . . . . . . . . . . . . . . . . . . . . . 36 


\section{[Intervention Review] \\ Internal versus external tocodynamometry during induced or augmented labour}

Jannet JH Bakker ${ }^{1}$, Petra F Janssen ${ }^{2}$, Karlijn van Halem ${ }^{1}$, Birgit Y van der Goes ${ }^{1}$, Dimitri N.M. Papatsonis ${ }^{3}$, Joris AM van der Post ${ }^{1}$, Ben Willem J Mol ${ }^{4}$

${ }^{1}$ Department of Obstetrics and Gynaecology, Academic Medical Center, Amsterdam, Netherlands. ${ }^{2}$ Department of Gynaecology and Obstetrics, VU University Medical Center, Amsterdam, Netherlands. ${ }^{3}$ Department of Obstetrics and Gynaecology, Amphia Hospital Breda, Breda, Netherlands. ${ }^{4}$ Obstetrics and Gynaecology, Academic Medical Centre, Amsterdam, Netherlands

Contact address: Jannet JH Bakker, Department of Obstetrics and Gynaecology, Academic Medical Center, Meibergdreef 9, Amsterdam, 1105 AZ, Netherlands. j.j.bakker@amc.nl.

Editorial group: Cochrane Pregnancy and Childbirth Group.

Publication status and date: New, published in Issue 12, 2012.

Review content assessed as up-to-date: 3 August 2012.

Citation: Bakker JJH, Janssen PF, van Halem K, van der Goes BY, Papatsonis DN, van der Post JAM, Mol BWJ. Internal versus external tocodynamometry during induced or augmented labour. Cochrane Database of Systematic Reviews 2012, Issue 12. Art. No.: CD006947. DOI: 10.1002/14651858.CD006947.pub2.

Copyright (C) 2012 The Cochrane Collaboration. Published by John Wiley \& Sons, Ltd.

\section{A B S T R A C T}

\section{Background}

Uterine contractions can be registered by external tocodynamometry (ET) or, after rupture of the membranes, by internal tocodynamometry (IT). Monitoring of the frequency of contractions is important especially when intravenous oxytocin is used as excessive uterine activity (hyperstimulation or tachysystole) can cause fetal distress. During induction of labour as well as during augmentation with intravenous oxytocin, some clinicians choose to monitor frequency and strength of contractions with IT rather than with ET as an intrauterine pressure catheter measures intrauterine activity more accurately than an extra-abdominal tocodynamometry device. However, insertion of an intrauterine catheter has higher costs and also potential risks for mother and child.

\section{Objectives}

To assess the effectiveness of IT compared with using ET when intravenous oxytocin is used for induction or augmentation of labour.

\section{Search methods}

We searched the Cochrane Pregnancy and Childbirth Group's Trials Register (11 April 2012) and PubMed (1966 to 7 March 2012 ).

\section{Selection criteria}

We included all published randomised controlled trials with data from women in whom IT was compared with ET in induced or augmented labour with oxytocin. We excluded trials that employed quasi-randomised methods of treatment allocation. We found no unpublished or ongoing studies on this subject.

\section{Data collection and analysis}

Two review authors independently assessed trial eligibility and risk of bias, and independently extracted data. Data were checked for accuracy. Where necessary, we contacted study authors for additional information. 


\section{Main results}

Three studies involving a total of 1945 women were included. Overall, risk of bias across the three trials was mixed. No serious complications were reported in the trials and no neonatal or maternal deaths occurred. The neonatal outcome was not statistically different between groups: Apgar score less than seven at five minutes (RR 1.78, 95\% CI 0.83 to 3.83; three studies, $\mathrm{n}=1945)$; umbilical artery $\mathrm{pH}$ less than 7.15 (RR $1.31,95 \%$ CI 0.95 to 1.79 ; one study, $\mathrm{n}=1456$ ); umbilical artery $\mathrm{pH}$ less than $7.16(\mathrm{RR} 1.23,95 \%$ CI 0.39 to 3.92; one study, $\mathrm{n}=239$ ); admission to the neonatal intensive care unit (RR 0.34, 95\% CI 0.07 to 1.67 ; two studies, $\mathrm{n}=$ 489); and more than 48 hours hospitalisation (RR 0.92, 95\% CI 0.71 to 1.20 ; one study, $\mathrm{n}=1456$ ). The pooled risk for instrumental delivery (including caesarean section, ventouse and forceps extraction) was not statistically significantly different (RR 1.05 , 95\% CI 0.91 to 1.21 ; three studies, $n=1945)$. Hyperstimulation was reported in two studies $(n=489)$, but there was no statistically significant difference between groups (RR 1.21, 95\% CI 0.78 to 1.88 ).

\section{Authors' conclusions}

This review found no differences between the two types of monitoring (internal or external tocodynamometry) for any of the maternal or neonatal outcomes. Given that this review is based on three studies ( $\mathrm{N}=1945$ women) of moderate quality, there is insufficient evidence to recommend the use of one form of tocodynamometry over another for women where intravenous oxytocin was administered for induction or augmentation of labour.

\section{PLAIN LANGUAGE SUMMARY}

\section{Internal versus external registration of contractions during induced or augmented labour}

Induction and augmentation of labour are common procedures within obstetric practice with various indications for mother and child. When contractions are stimulated by intravenous oxytocin, registration of the frequency of contractions is important for determination of the right dosage of medication. Uterine contractions can be monitored through the abdominal wall of the mother by using a small device that is placed on the skin using a belt to hold it in position, where the device measures changes in the shape of the uterus (external tocodynamometry (ET)), or by positioning an intrauterine pressure catheter inside the uterus next to the baby (internal tocodynamometry (IT)). Use of IT is only possible after rupture of the membranes and is an easy, painless procedure done during vaginal examination by the midwife or doctor in charge. During induction or augmentation of labour with intravenous oxytocin, some clinicians choose to monitor contractions with an IT rather than with ET. An intrauterine pressure catheter measures the contractions more accurately and could result in a better dosage of the oxytocin. This could, therefore, reduce the risk of hyperstimulation, for example too frequent contractions, and subsequently reduce the risk for fetal distress. Moreover with the modern central monitoring systems and the accurate registration with the use of IT there is no need for the caregivers to be physical present in the labour room to assess the frequency of contractions. However, besides higher costs of IT, insertion of an intrauterine catheter in the uterus of the mother has rare but potentially hazardous risks for both mother and child, like placental and fetal vessel damage.

The aim of this review was to compare the effectiveness of IT compared with ET. We included three randomised controlled studies (1945 women). The methodological quality of the studies was considered to be moderate. When comparing internal registration of contractions with external registration of contractions during induced or augmented labour, there were no differences in any of the outcomes for mother or child: adverse neonatal outcomes, instrumental deliveries, caesarean section, use of analgesia or time to delivery. No increased risk for infection was reported when an intrauterine catheter was used in these studies.

There is insufficient evidence to recommend the use of one form of tocodynamometry over another for women where intravenous oxytocin is administered for induction or augmentation of labour.

Internal versus external tocodynamometry during induced or augmented labour (Review) 


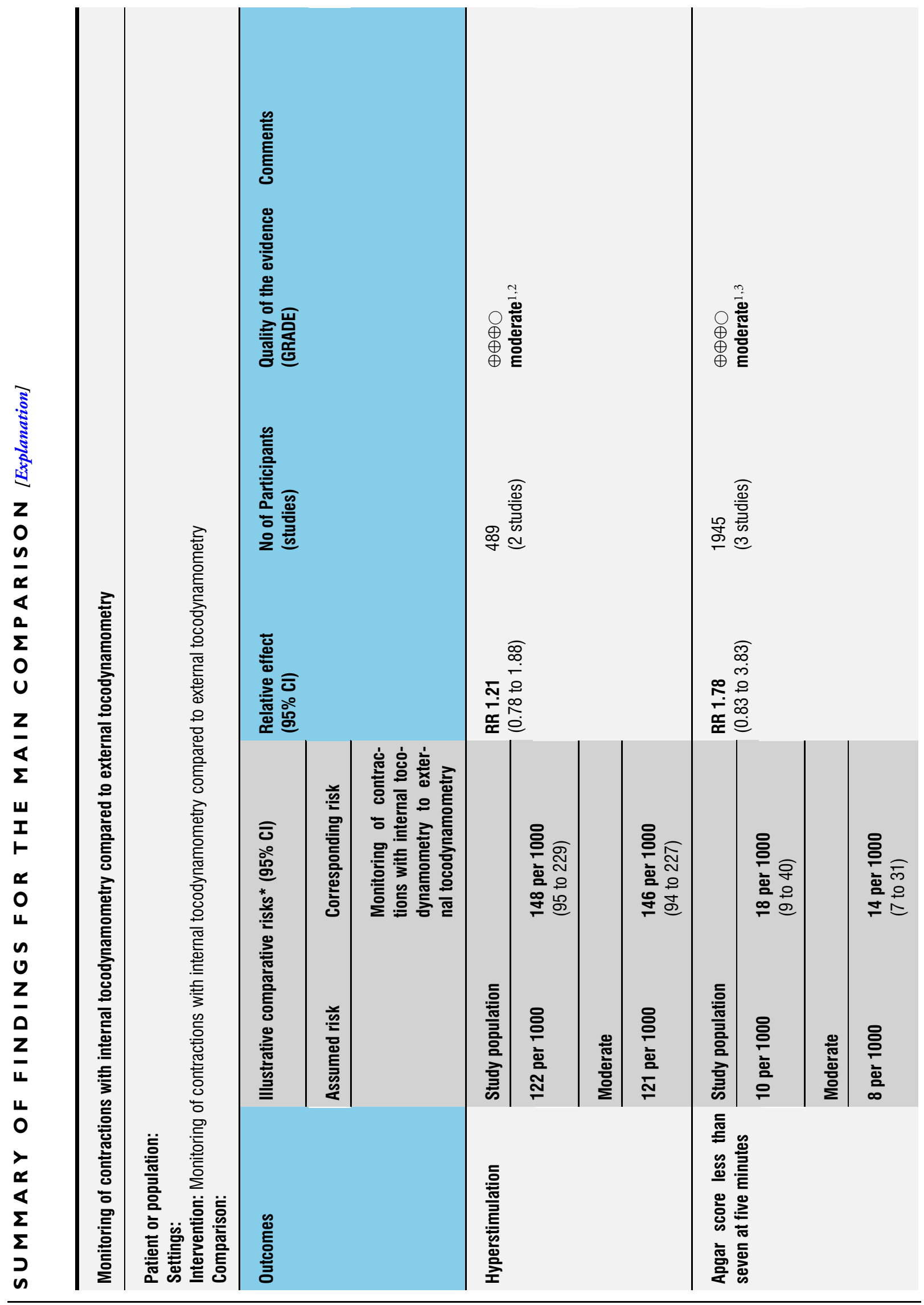

Internal versus external tocodynamometry during induced or augmented labour (Review)

Copyright @ 2012 The Cochrane Collaboration. Published by John Wiley \& Sons, Ltd. 


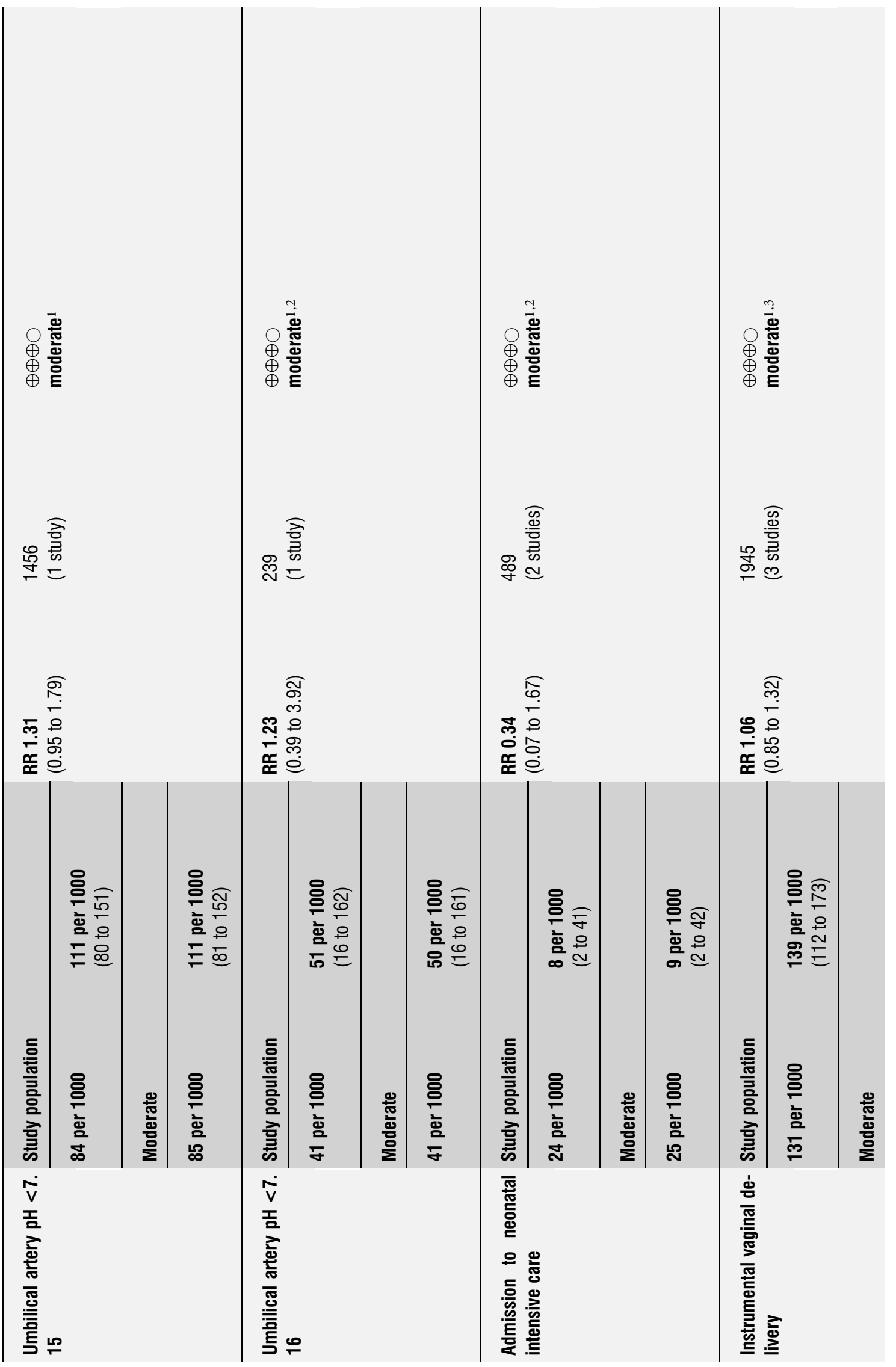

Internal versus external tocodynamometry during induced or augmented labour (Review)

Copyright @ 2012 The Cochrane Collaboration. Published by John Wiley \& Sons, Ltd. 


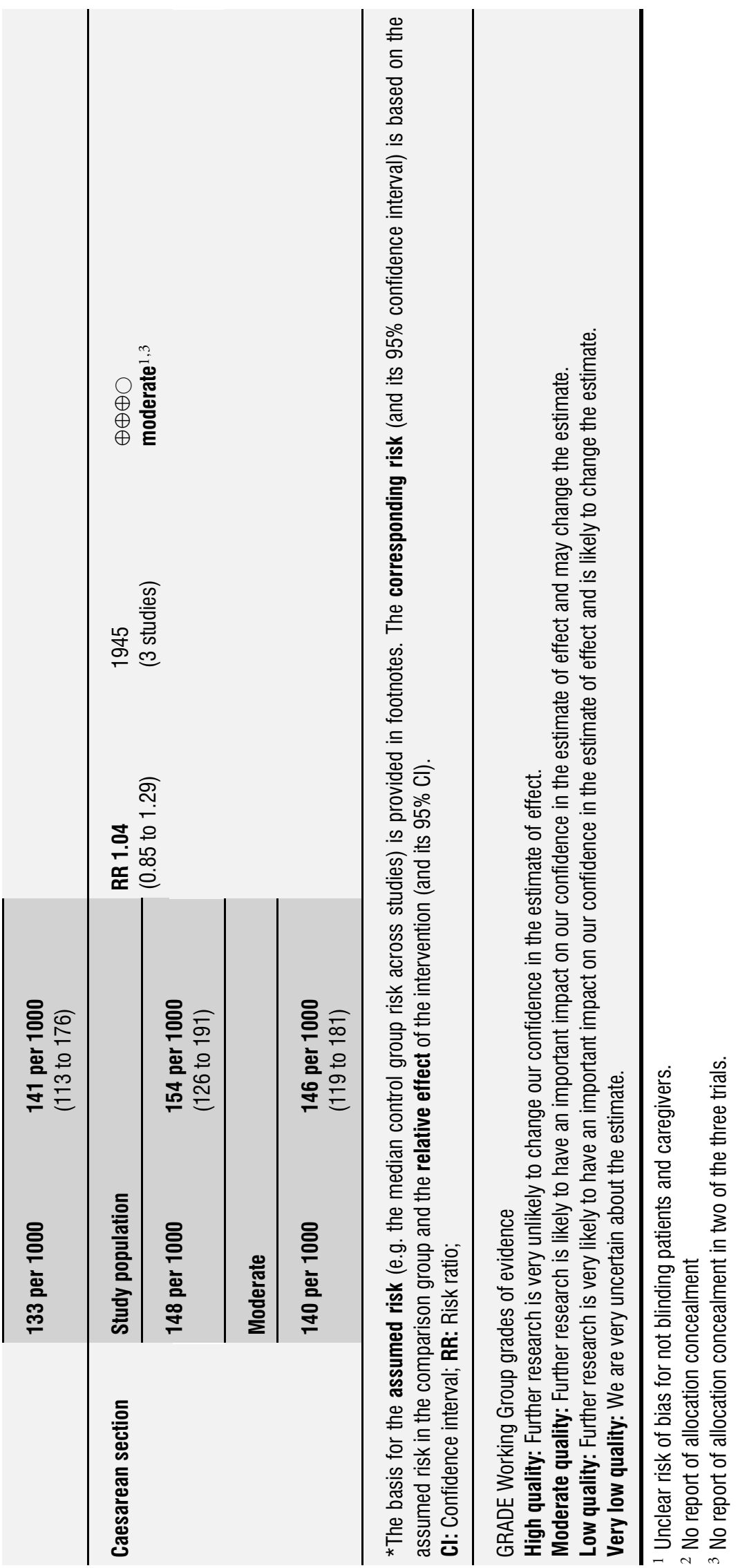

Internal versus external tocodynamometry during induced or augmented labour (Review)

Copyright @ 2012 The Cochrane Collaboration. Published by John Wiley \& Sons, Ltd. 


\section{B A C K G ROU N D}

\section{Oxytocin in labour}

Since 1906 the contractile properties of oxytocin on uterine myometrial smooth muscle has been described (Dale 1906). Initially, an extract of the posterior pituitary was used for treatment of postpartum bleeding. Since the cloning of the gene in 1983, synthetic oxytocin is now produced in different forms by pharmaceutical companies (Land 1983). Oxytocin is usually administered in a diluted intravenous infusion; it cannot be administered orally because it is quickly metabolized in the gastrointestinal tract. Uterine muscle cells respond rapidly to administration, within three to five minutes, and a steady state is achieved within 40 minutes (Smith 2006). Oxytocin is quickly metabolized by several enzymes including peptidases in the kidneys and oxytocinase excreted by the placenta (Smith 2006).

Adminstration of intravenous oxytocin is the most common intervention in obstetrical care and is used for induction of labour as well as for augmentation in cases of arrest of labour. Oxytocin has a positive impact on the strength and frequency of contractions. Some obstetricians combine low amniotomy with intravenous oxytocin titrations immediately following or within an hour, while others advocate a delay of four to six hours (MacKenzie 2006). A Cochrane review demonstrated that the combination of oxytocin administration for induction with amniotomy compares well with other forms of induction (Howarth 2001). Another Cochrane review demonstrated that use of prostaglandins is more effective than oxytocin alone for ripening of the cervix in the case of an unfavourable cervix, but that oxytocin is as effective when used alone in women with ruptured membranes (Alfirevic 2009).

\section{Oxytocin complications}

Potential complications caused by the use of intravenous oxytocin for induction or augmentation of labour are hyponatraemia, hypotension and hyperstimulation (Smith 2006).

Hyponatraemia is an electrolyte disturbance in which the sodium concentration in the serum is below $135 \mathrm{mEq} / \mathrm{L}$. Excessive uterine activity (hyperstimulation or tachysystole) is defined by the American College of Obstetricians and Gynecologists (ACOG) as more than five contractions in 10 minutes, lasting at least two minutes, or contractions of normal duration within one minute of each other (ACOG 2009). When contractions are too frequent, the recovery period between contractions shortens and this may affect fetal oxygenation, cause fetal hypoxia and even lead to brain damage. On the other hand, signs of fetal hypoxia increase the risk for instrumental delivery and consequently iatrogenic damage to mother and child. Reducing the risk of hyperstimulation and thus fetal hypoxia by accurate measurement of contractions could therefore lead to a reduction in fetal and maternal morbidity.

\section{Internal tocodynamometry complications}

Intrauterine pressure catheter placement, a routine procedure in labour and delivery, has the possibility of infrequent but potentially hazardous risks for mother and child. Insertion of an intrauterine catheter during labour is usually an easy procedure to accomplish. In the literature, however, there have been reports of an increased risk of intrauterine infections and repeated case reports of placental or fetal vessel damage despite management lege artis (Soper 1989; Handwerker 1995; Soper 1996; Lind 1999; Wilmink 2008). Extramembranous placement occurs $14 \%$ to $38 \%$ of the time (Lind 1998), with adverse events occurring in one in 1400 placements (Chan 1973; Trudinger 1978). More recently two cases were reported with an anaphylactoid syndrome of pregnancy, previously known as amniotic fluid embolism, after Intrauterine pressure catheter placement. This was expressed as a life threatening anaphylactic reaction with acute onset of severe hypoxia, neurologic sequelae, and haemodynamic collapse with subsequent cardiopulmonary failure followed by disseminated intravascular coagulation (Matsuo 2008; Harbison 2010).

\section{Internal tocodynamometry versus external tocodynamometry}

Uterine contractions can be assessed by palpation of the fundus of the uterus and observation of the mother. With this method the obstetrician gets a snapshot and no long term hard copy registration of the contraction in relation to the fetal heart rate. Therefore, this method will not be included.

External tocodynamometry (ET) is a method that continuously records contractions by using a belt to place a transducer on the fundus; these recordings are affected by maternal movements. ET measures the change of the shape of the uterus in relation to the abdominal wall during a contraction. This method is used to measure the frequency of the contractions, but not the intrauterine change of pressure.

Internal tocodynamometry (IT) monitors uterine activity with a strain gauge (an intrauterine pressure catheter) inserted into the cavity of the uterus next to the fetus, which provides data on the frequency and duration of uterine contractions. Insertion of an intrauterine pressure catheter is done during a vaginal examination and is a simple procedure that is carried out by both midwives and doctors. The device measures the intrauterine pressure, expressed in Montevideo units, at rest and during contractions.

All methods provide good information on the frequency of contractions and an indication of their duration.

Both during induction of labour as well as augmentation, some clinicians choose to monitor the frequency and strength of contractions with IT rather than ET, as IT measures intrauterine activity more accurately (Bakker 2008). There are several arguments in favour of IT. 
1. When using oxytocin, exact monitoring of contractions is demanded in order to prevent hyperstimulation. ET does not accurately register contractions in all women and in all positions of the labouring woman so it can underestimate the uterine contractions, which may lead to excessive use of oxytocin and thus hyperstimulation. Some state that the use of IT, by accurately measuring uterine contractions, leads to a more moderate amount of oxytocin and reduces the risk of hyperstimulation.

2. Among women in their child bearing years, $8 \%$ have severe obesity with a body mass index above $40 \mathrm{~kg} / \mathrm{m}^{2}$ (Euliano 2007). This group have more obstetric complications such as preeclampsia and gestational diabetes. Induction of labour is common in this group of women and uterine activity can be difficult to assess with ET. The distance from the external tocodynamometer on the skin to the uterine wall could be such that reliable measurement of uterine contractions is not possible. IT could therefore be more useful in this group of women.

3. Some argue that the use of IT might facilitate the clinical diagnosis of uterine rupture, especially in women with a previous caesarean section, because the expectation is that the pressure inside the uterine cavity flattens and lowers when the uterine wall is ruptured. This, however, is not supported by the literature (Rodriquez 1989). In this review of 76 cases of uterine rupture, 39 were monitored with an intrauterine pressure catheter. The classic description of a loss of intrauterine pressure or cessation of labour was not observed in any of the patients.

Furthermore, routine use of IT in every induced or augmented woman is costly as the rates of induction and augmentation are increasing. Labour induction rates in the United States has risen from less than $10 \%$ of deliveries to more than $22 \%$ between 1990 and 2008; and augmentation took place in more than $20 \%$ of all deliveries in 2008 according to data from the Centers for Disease Control and Prevention (Osterman 2011). Routine use of IT in $40 \%$ of all deliveries would add significant public health costs, of roughly USD 200 million/year.

\section{O B J E C T I VES}

The primary aim of this review was to evaluate the effectiveness of internal tocodynamometry (IT) compared with external tocodynamometry (ET) when intravenous oxytocin is used for induction or augmentation of labour.

\section{Types of studies}

We included all published, unpublished and ongoing randomised controlled trials in which IT was compared with external monitoring or no monitoring in women undergoing induction or augmentation of labour with oxytocin. Cluster-randomised trials and trials using a crossover design were excluded. We excluded trials that employed quasi-randomised methods of treatment allocation.

\section{Types of participants}

Pregnant women undergoing induction of labour or augmentation of labour with intravenous oxytocin.

\section{Types of interventions}

Insertion of all types of intrauterine pressure catheters during labour compared with ET or no monitoring.

\section{Types of outcome measures}

\section{Primary outcomes}

- Uterine rupture

- Hyperstimulation

- Apgar score less than seven at five minutes

- Umbilical artery pH

- Admission of newborn to neonatal intensive care unit

\section{Secondary outcomes}

These included other measures of effectiveness, complications and health service use.

\section{Maternal}

- Mode of delivery

- Number of instrumental deliveries

- Antepartum haemorrhage

- Postpartum haemorrhage

- Placental or fetal vessel damage

- Duration of hospital stay

- Serious maternal outcomes (defined as death, coma, cardiac arrest, respiratory arrest, use of a mechanical ventilator, admission to intensive care unit)

- Maternal infection

- Women's satisfaction

\section{Neonatal}

- Time to delivery

- Neonatal morbidity

- Neonatal infection

- Respiratory distress syndrome 
- Use of mechanical ventilation

- Intraventricular haemorrhage

- Neonatal jaundice

- Neonatal sepsis

- Neonatal death

\section{Health service}

- Neonatal length of hospital stay

- Maternal admission to intensive care unit

- Total hospital costs

- Use of health services

\section{Search methods for identification of studies}

\section{Electronic searches}

We searched the Cochrane Pregnancy and Childbirth Group's Trials Register by contacting the Trials Search Co-ordinator (11 April 2012).

The Cochrane Pregnancy and Childbirth Group's Trials Register is maintained by the Trials Search Coordinator and contains trials identified from:

1. monthly searches of the Cochrane Central Register of Controlled Trials (CENTRAL);

2. weekly searches of MEDLINE;

3. weekly searches of EMBASE;

4. handsearches of 30 journals and the proceedings of major conferences;

5. weekly current awareness alerts for a further 44 journals plus monthly BioMed Central email alerts.

Details of the search strategies for CENTRAL, MEDLINE and EMBASE, the list of handsearched journals and conference proceedings, and the list of journals reviewed via the current awareness service can be found in the 'Specialized Register' section within the editorial information about the Cochrane Pregnancy and Childbirth Group.

Trials identified through the searching activities described above were each assigned to a review topic (or topics). The Trials Search Coordinator searched the register for each review using the topic list rather than keywords.

In addition, we searched PubMed (1966 to 7 March 2012) using the search terms detailed in Appendix 1.

We did not apply any language restrictions.

\section{Data collection and analysis}

\section{Selection of studies}

Two review authors, PF Jansen (PJ) and JJH Bakker(JB), independently assessed all the potential studies identified as a result of the search strategy. BY van der Goes (BG) was asked to assess the Bakker 2010 trial as she was not involved in the conducting or writing up of this study. Disagreements were resolved through discussion.

\section{Data extraction and management}

We designed a form to extract data. For eligible studies, two review authors $\mathrm{PJ}$ and JB independently extracted the data using the agreed form. For the Bakker 2010 trial, co-author BG was asked to extract data from the trial. We resolved discrepancies through discussion. We used the Review Manager software (RevMan 2011) to double enter all the data, or a subsample. When information regarding any of the above was unclear, we attempted to contact the authors of the original reports for them to provide additional information or data.

\section{Assessment of risk of bias in included studies}

Two authors (PJ and JB) independently assessed the risk of bias for each study using the criteria outlined in section 8 of the Cochrane Handbook for Systematic Reviews of Interventions (Higgins 2011). There was no disagreement. We considered two major sources of potential bias and the methods of avoidance of these biases when assessing trial quality. Moreover, we looked specifically at declared sample size calculations, defined inclusion and exclusion criteria, baseline comparability and whether a conflict of interest was present, absent or unclear.

\section{(I) Random sequence generation (checking for possible selection bias)}

We described for each included study the method used to generate the allocation sequence to allow an assessment of whether it should produce comparable groups.

We assessed the method as:

- low risk of bias (any truly random process, e.g. random number table; computer random number generator);

- high risk of bias (any non-random process, e.g. odd or even date of birth; hospital or clinic record number); or

- unclear risk of bias.

\section{(2) Allocation concealment (checking for possible selection bias)}

We described for each included study the method used to conceal allocation to interventions prior to assignment and assessed whether intervention allocation could have been foreseen in advance of or during recruitment, or changed after assignment. We assessed the methods as:

- low risk of bias (e.g. telephone or central randomisation; consecutively numbered sealed opaque envelopes); 
- high risk of bias (open random allocation; unsealed or nonopaque envelopes; alternation; date of birth);

- unclear risk of bias.

\section{(3.1) Blinding of participants and personnel (checking for possible performance bias)}

We described for each included study the methods used, if any, to blind study participants and personnel from knowledge of which intervention a participant received. We considered that studies were at low risk of bias if they were blinded, or if we judged that the lack of blinding would be unlikely to affect results. We assessed blinding separately for different outcomes or classes of outcomes. We assessed the methods as:

- low, high or unclear risk of bias for participants;

- low, high or unclear risk of bias for personnel.

\section{(3.2) Blinding of outcome assessment (checking for possible detection bias)}

We described for each included study the methods used, if any, to blind outcome assessors from knowledge of which intervention a participant received. We assessed blinding separately for different outcomes or classes of outcomes.

We assessed methods used to blind outcome assessment as:

- low, high or unclear risk of bias.

(4) Incomplete outcome data (checking for possible attrition bias due to the amount, nature and handling of incomplete outcome data)

We described for each included study, and for each outcome or class of outcomes, the completeness of data including attrition and exclusions from the analysis. We stated whether attrition and exclusions were reported and the numbers included in the analysis at each stage (compared with the total number of randomised participants), reasons for attrition or exclusion where reported, and whether missing data were balanced across groups or were related to outcomes. Where sufficient information was reported, or could be supplied by the trial authors, we re-included missing data in the analyses which we undertook.

We assessed methods as:

- low risk of bias (e.g. no missing outcome data; missing outcome data balanced across groups);

- high risk of bias (e.g. numbers or reasons for missing data imbalanced across groups; 'as treated' analysis done with substantial departure of the intervention received from that assigned at randomisation);

- unclear risk of bias.

\section{(5) Selective reporting (checking for reporting bias)}

We described for each included study how we investigated the possibility of selective outcome reporting bias and what we found.
We assessed the methods as:

- low risk of bias (where it was clear that all of the study's prespecified outcomes and all expected outcomes of interest to the review have been reported);

- high risk of bias (where not all the study's pre-specified outcomes have been reported; one or more reported primary outcome was not pre-specified; outcomes of interest were reported incompletely and so cannot be used; study failed to include results of a key outcome that would have been expected to have been reported);

- unclear risk of bias.

\section{(6) Other bias (checking for bias due to problems not covered by (I) to (5) above)}

We described for each included study any important concerns we had about other possible sources of bias.

We assessed whether each study was free of other problems that could put it at risk of bias:

- low risk of other bias;

- high risk of other bias;

- unclear whether there was a risk of other bias.

\section{(7) Overall risk of bias}

We made explicit judgements about whether studies were at high risk of bias, according to the criteria given in the Handbook for Systematic Reviews of Interventions (Higgins 2011). With reference to (1) to (6) above, we assessed the likely magnitude and direction of the bias and whether we considered it likely to impact on the findings. We explored the impact of the level of bias through undertaking sensitivity analyses (see Sensitivity analysis).

\section{Measures of treatment effect}

We carried out statistical analysis using the Review Manager software (RevMan 2011). We used fixed-effect model meta-analysis for combining data in the absence of significant heterogeneity if trials were sufficiently similar. If heterogeneity was found, this was explored by sensitivity analysis followed by use of a random-effects model if required. Probable causes of heterogeneity could be the body mass index (BMI) of the woman in labour, parity, gestational age and birthweight.

\section{Dichotomous data}

For dichotomous data, we presented results as summary relative risk with $95 \%$ confidence interval.

\section{Continuous data}

For continuous data, we used the median as outcomes were measured in the same way between trials. 


\section{Dealing with missing data}

For included studies, we noted levels of attrition. We explored the impact of including studies with high levels of missing data in the overall assessment of treatment effect by using sensitivity analysis. For all outcomes we carried out analyses, as far as possible, on an intention-to-treat basis. That is, we attempted to include all participants randomised to each group in the analyses, and all participants were analysed in the group to which they were allocated regardless of whether or not they received the allocated intervention. The denominator for each outcome in each trial was the number randomised minus any participants whose outcomes were known to be missing.

\section{Assessment of heterogeneity}

We assessed statistical heterogeneity in each meta-analysis using the $\mathrm{T}^{2}, \mathrm{I}^{2}$ and $\mathrm{Chi}^{2}$ statistics. We regarded heterogeneity as substantial if $\mathrm{I}^{2}$ was greater than $30 \%$ and either $\mathrm{T}^{2}$ was greater than zero or there was a low $\mathrm{P}$ value (less than 0.10 ) in the $\mathrm{Chi}^{2}$ test for heterogeneity.

\section{Assessment of reporting biases}

In future updates of this review, if there are 10 or more studies in the meta-analysis we will investigate reporting biases (such as publication bias) using funnel plots. We will assess funnel plot asymmetry visually, and also use formal tests for funnel plot asymmetry. For continuous outcomes we will use the test proposed by Egger 1997, and for dichotomous outcomes we will use the test proposed by Harbord 2006. If asymmetry is detected in any of these tests or is suggested by a visual assessment, we will perform exploratory analyses to further investigate the causes.

\section{Data synthesis}

We carried out statistical analysis using the Review Manager software (RevMan 2011). We used fixed-effect model meta-analysis for combining data where it was reasonable to assume that studies were estimating the same underlying treatment effect; that is where trials were examining the same intervention, and the trials' populations and methods were judged sufficiently similar. If there was clinical heterogeneity sufficient to expect that the underlying treatment effects would differ between trials, or if substantial statistical heterogeneity was detected, we explored the reason for the heterogeneity by subgroup analysis. We discussed the clinical implications of treatment effects differing between trials. If the average treatment effect was not clinically meaningful we did not combine trials.

\section{Subgroup analysis and investigation of heterogeneity}

If we identified substantial heterogeneity, we investigated it using subgroup analyses and sensitivity analyses. We considered whether an overall summary was meaningful and, if it was, used randomeffects model meta-analysis to produce it. We planned to carry out the following subgroup analyses for the outcome duration of labour':

1. induction of labour;

2. augmentation of labour.

We planned to carry out subgroup analysis in the group of women with a previous caesarean section.

For fixed-effect model inverse variance meta-analyses we assessed differences between subgroups by interaction tests. For randomeffects and fixed-effect model meta-analyses using methods other than inverse variance, we assessed differences between subgroups by inspection of the confidence intervals; non-overlapping confidence intervals indicate a statistically significant difference in treatment effect between the subgroups.

\section{Sensitivity analysis}

In future updates of this review, as more data become available, we will carry out sensitivity analysis to explore the effect of trial quality if trials of differing quality are included in the review. This will involve analysis based on our assessment of whether trials are at risk of selection bias or attrition bias. Studies of poor quality (those rated as 'high' or 'unclear' risk of bias for sequence generation, allocation concealment, or incomplete outcome data) will be excluded in the analysis in order to assess any substantive difference compared to the overall result.

\section{RES U L T S}

\section{Description of studies}

See: Characteristics of included studies; Characteristics of excluded studies.

\section{Results of the search}

The search of the Pregnancy and Childbirth Group Trials Register found 14 reports and our search of PubMed found 189. After screening the titles and abstracts we selected 25 reports of 19 studies. We included three and excluded 16 titles. Two review authors (PJ and JB) independently assessed all the potential studies identified as a result of the search strategy. Both authors used a data form to assess the quality of the studies and extract data from the included studies. There were four potentially eligible randomised controlled trials with a randomised comparison of external tocodynamometry (ET) and internal tocodynamometry (IT). We found no unpublished or ongoing studies on this subject. 


\section{Included studies}

We included three studies (Chua 1990; Chia 1993; Bakker 2010) involving 1945 women. Furthermore we used the report of van Halem 2011, a follow up of the randomised controlled trial of Bakker 2010, that contained data for the infection outcome. The two studies of Chia and Chua were performed in Singapore, and the third study was performed in the Netherlands. All studies were in hospital settings. The methodological quality of the trials was considered good. The three randomised controlled trials had good comparable methods and outcomes. In the trials of Chia 1993 and Chua 1990 it remained unclear whether the study population included women with a previous caesarean section. In the trial of Bakker 2010 women with a previous caesarean section were excluded.

For details of the included studies, see the table Characteristics of included studies.

\section{Excluded studies}

We excluded 16 studies. There were many publications about intra- and extramembranous placement of the catheter, differences between different types of catheters and case reports about adverse events. We did not include these studies in this review but focused on the randomised comparison of ET and IT. We agreed to exclude one study that compared ET and IT, the study of Panayotopoulos 1998 , because of the invalid randomisation method, which involved selecting every second case and ended up with two unequal study groups. We did not identify any studies comparing tocodynamometry with no monitoring.

For details of excluded studies, see the table Characteristics of excluded studies.

\section{Risk of bias in included studies}

\begin{abstract}
Allocation
The Bakker 2010 trial used a central, computerised randomisation program that provided the allocation of included women at the different study sites, so it was ensured that the sequence was concealed. Women in the studies of Chia 1993 and Chua 1990 were randomly allocated to the different methods of tocography by using a random number table; this method was acceptable at the time and has a low risk of selection bias. Chia 1993 and Chua 1990 reported no losses to follow up and they did not keep a record of eligible non-randomised women. The trial by Bakker 2010 reported no losses to follow up cases but had a substantial number of non-participants. More than $72 \%$ of the eligible women declined participation or were not informed about the trial due to various reasons, mostly workload of the caregivers (information first author). We judged adequate generation of the randomisation sequence in all three trials and the risk for bias was low.
\end{abstract}

\section{Blinding}

Due to the nature of the interventions, in all included studies the allocation was not blinded for the doctor or the women. Although it is highly unlikely that women or caregiver knowledge of the allocation could influence outcomes, the lack of blinding downgraded the level of quality assessment of findings. In the study of van Halem 2011, the assessor of the medical files was blinded to the allocation.

\section{Incomplete outcome data}

The trial by Bakker 2010 reported the outcomes according the intention-to-treat principle, that is the women were analysed in the group they were allocated to; and also according to the per protocol principle, that is the women were analysed in the group with the treatment they actually received. Chia 1993 and Chua 1990 reported no crossover in their study groups. For the pooled risk we used the data from the intention-to-treat analysis.

\section{Selective reporting}

The included studies had clear and specific pre-specified outcomes and so appeared to be free of selective reporting. The trial by Bakker 2010 did not report the outcome hyperstimulation. In the study protocol published in the trials register this outcome was not planned.

\section{Effects of interventions}

See: Summary of findings for the main comparison Monitoring of contractions with internal tocodynamometry compared to external tocodynamometry

\section{Primary outcomes}

Uterine rupture did not occur in any of the three trials. Hyperstimulation was reported in two of the included trials, Chia 1993 and Chua 1990 (involving 489 women), but was not different between the study groups (risk ratio (RR) 1.21, 95\% confidence interval (CI) 0.78 to 1.88; Analysis 1.2).

The neonatal outcome was no different between the control group which used ET and the intervention group which used an intrauterine pressure catheter. An Apgar score less than seven at five minutes was reported in all included trials and was not statistically significantly different between groups (RR 1.78, 95\% CI 0.83 to 3.83; $\mathrm{N}=1945$; Analysis 1.3). Umbilical artery $\mathrm{pH}$ less than 7.15 was reported in one trial (Bakker 2010) (RR 1.31, 95\% CI 0.95 to $1.79 ; \mathrm{N}=1456$; Analysis 1.4); $\mathrm{pH}$ less than 7.16 was reported in the trial of Chia 1993 (RR 1.23, 95\% CI 0.39 to $3.92 ; \mathrm{N}=$ 239; Analysis 1.6). Admission to the neonatal intensive care unit was reported in two studies (Chua 1990; Chia 1993) and was not statistically significantly different between groups (RR 0.34, 95\% 
CI 0.07 to 1.67; $\mathrm{N}=489$; Analysis 1.7). One study (Bakker 2010) reported more than 48 hours hospitalisation instead (RR 0.92, 95\% CI 0.71 to $1.20 ; \mathrm{N}=1456$; Analysis 1.8 ).

\section{Secondary outcomes}

There were no serious complications, like placenta or vessel perforation, or abruptio placentae, reported in the trials from the use of the intrauterine pressure catheter, and no neonatal deaths or serious maternal complications (defined as death, coma, cardiac arrest, respiratory arrest, use of a mechanical ventilator, admission to intensive care unit) occurred in either study group. All three studies reported rates of instrumental vaginal delivery and caesarean section. The pooled risk for instrumental delivery (caesarean section, ventouse and forceps extraction) was not statistically significant different (RR 1.05, 95\% CI 0.9 to 1.2 ; three studies, $\mathrm{N}=1945$; Analysis 1.11). There was variance between the studies. The differences in crude percentages between the studies were probably due to the different policies and increasing interventions in obstetrics over time (1993 versus 2010), but most of all the variance was due to different etiology: induced labour versus augmented labour in cases of arrest of labour. Therefore, we performed a subgroup analysis. The pooled risk for instrumental delivery for women with induced labour was more in favour of IT yet not statistically significantly different (RR 0.91, 95\% CI 0.75 to 1.1; two studies, $\mathrm{N}=1195$; Analysis 1.11). The pooled risk for instrumental delivery for women with augmented labour, however, was in favour of ET and just statistically significantly different (RR 1.25, 95\% CI 1.02 to 1.5; two studies, $\mathrm{N}=750$; Analysis 1.11). The interaction test for subgroup differences was significant for this subgroup analysis $(P=0.02$; Analysis 1.11$)$ suggesting a difference between the induced and augmented subgroups. When the risk for instrumental delivery was specified as vaginal instrumental delivery or operative delivery (that is caesarean section) the difference between the augmented group women and the induced group women disappeared. The pooled risk for a caesarean section was not statistically significant between study groups (RR 1.04, 95\% CI 0.85 to 1.29; three studies, $\mathrm{N}=1945$; Analysis 1.13). This CI corresponds to a plausible reduction of the caesarean section rate of $15 \%$ up to a nearly $30 \%$ increase. The risk for caesarean section was not different between the subgroups. The pooled risk for vaginal instrumental deliveries (ventouse or forceps extraction) was not statistically significant different (RR 1.06, 95\% CI 0.85 to 1.32; three studies, $\mathrm{N}=1945$; Analysis 1.12).

There was no increased risk of infection when an intrauterine catheter was used: infection during labour (RR 0.69, 95\% CI 0.44 to 1.08; one study, $\mathrm{N}=1456$; Analysis 1.17), and no increased risk of infection in mother or child up to three weeks postpartum (van Halem 2011) (RR 0.84, 95\% CI 0.61 to 1.16 ; one study, N = 1435; Analysis 1.16). For the outcome "infection up to three weeks postpartum", women with an indication for prophylactic antibiotic during labour (i.e. for known positive Group B strep- tococcus (GBS) status, heart disease, or other reasons for prophylaxis) were excluded for analysis.

Median times to delivery in the subgroups induced and augmented labour were not statistically significantly different between study groups (see Table 1).

Mean time to delivery was extracted for this review from the dataset of the Bakker 2010 trial, no statistically significant difference was found between the groups (mean difference (MD) - 15.60 minutes, 95\% CI -40.99 to 9.79 ; 1 study, $\mathrm{N}=1456$; Analysis 1.14).

Other secondary outcomes were not reported (antepartum or postpartum haemorrhage, duration of hospital stay for mother or child, women's satisfaction; specified neonatal outcomes like respiratory distress syndrome, use of mechanical ventilation, intraventricular haemorrhage, neonatal jaundice or sepsis; total hospital costs, use of health service).

No subgroup analysis could be performed for women with a previous caesarean section.

\section{I S C USSION}

The aim of this review was to compare the effectiveness of IT compared with ET. We included three randomised controlled studies (1945 women) of moderate quality. The results suggest no benefit for the routine use of internal tocodynamometry (IT) for monitoring contractions in women with induced or augmented labour with intravenous oxytocin. However, there is insufficient evidence to recommend the use of one form of tocodynamometry over another form for women where intravenous oxytocin is administered for induction or augmentation of labour.

\section{Summary of main results}

Three studies were included in this review. Although on theoretical grounds one might expect a better neonatal outcome and a more effective stimulation when the contractions are accurately measured, the robust results of the included studies do not support this concept. The pooled risk for instrumental delivery was not statistically different between study groups, however in the subgroup of women with augmented labour there was a just statistically significant difference in favour of ET. When the variable instrumental delivery was specified into instrumental vaginal delivery or caesarean section, this benefit for ET was not found; moreover we lack a clinical explanation for a possible advantage of external registration of contractions when labour is augmented. This review found insufficient evidence for a benefit of the routine use of IT on rates of adverse neonatal outcomes, rates of instrumental deliveries, use of analgesia, infection, or time to delivery. Moreover, case reports state that IT has rare but serious risks, including placental or fetal-vessel damage, infection and anaphylactic shock. 
In this review involving 922 women who were monitored with IT tocodynamometry, no such events occurred.

\section{Overall completeness and applicability of evidence}

In the Bakker 2010 trial, $12 \%$ of the women assigned to external monitoring were nonetheless treated with an intrauterine pressure catheter at the physician's discretion. The protocol of this study permitted crossover if cervical progression was absent for two hours, the frequency of uterine contractions was not sufficient, or caesarean section was being considered. These $12 \%$ of women were more likely to be primiparous ( $82.6 \%$ versus $63.2 \%)$, had a higher mean pre-pregnancy BMI (27.4 versus 25.3), and were more likely to have hypertension or pre-eclampsia $(33.8 \%$ versus $10.3 \%$ ); they were also more likely to have a caesarean section $(33.0 \%$ versus $16.0 \%)$. Analysis per protocol, for example according to the treatment actually given, had similar results in the rate of operative deliveries and for adverse neonatal outcomes. The two smaller studies (Chua 1990; Chia 1993) did not report crossover between study groups.

The study population of this review included women who were treated with intravenous oxytocin to stimulate contractions but did not involve women with a previous caesarean section. Whether an intrauterine pressure catheter should be used in these women is still controversial. Some clinicians state that the risk for uterus rupture is increased because of insertion of the catheter; others advocate the use of IT in women with a previous caesarean section, because they expect that the diagnosis of uterus rupture is easier. This review does not answer this question for this subgroup of women.

\section{Quality of the evidence}

The methodological quality of the trials was considered moderate.

\section{Potential biases in the review process}

We acknowledge that there is always a possibility of introducing bias at every stage of the review process. We attempted to minimise bias in a number of ways; two review authors independently assessed eligibility for inclusion and risk of bias, and carried out data extraction; moreover, assessment and data extraction of the largest trial (Bakker 2010) was done by a review co-author (BG) who was not involved in the trial.

\section{Agreements and disagreements with other studies or reviews}

The three included studies agree in their conclusion that there is no benefit with routine IT.

\section{A U THORS'CONCLUSIONS}

\section{Implications for practice}

There is insufficient evidence to recommend the use of one form of tocodynamometry over another for women where intravenous oxytocin is administered for induction or augmentation of labour.

In women with lack of progress of labour, cervical progression absent for two hours, or unclear frequency of uterine contractions, one-to-one observation of the labouring woman and her contractions is a realistic alternative to IT in the absence of a non-invasive alternative.

\section{Implications for research}

Future trials could focus on examining the strength of contractions during labour by improving the quality of extra-abdominal methods. These trials should include hyperstimulation and women's satisfaction.

\section{ACKNOW LEDGEMENTS}

We thank Dr R Scholten from the Dutch Cochrane Centre for his advice during preparation of the review.

We thank Dr JM van Lith for contributing to the protocol.

We acknowledge the Cochrane Childbirth and Pregnancy group for their valuable feedback.

As part of the pre-publication editorial process, this review has been commented on by three peers (an editor and two referees who are external to the editorial team), a member of the Pregnancy and Childbirth Group's international panel of consumers, and the Group's Statistical Adviser. 


\section{R E F E R E N C E S}

\section{References to studies included in this review}

Bakker 2010 \{published data only\}

* Bakker JJH, Verhoeven CJM, Janssen PF, van Lith JM, van Oudgaarden ED, Bloemenkamp KWM, et al.Outcomes after internal versus external tocodynamometry for monitoring labor. The New England Journal of Medicine 2010;362(4):306-13.

Van der Post JAM, Bakker JJH. Intra uterine pressure monitoring for augmentation or induction of labour with intravenous oxytocin: benefits and costs. Netherlands Trial Register (http://www.trialregister.nl) (accessed 1 November 2005).

van Halem K, Bakker JJH, Verhoeven CJ, Papatsonis DN, van Oudgaarden ED, Janssen PF, et al.Does use of an intrauterine catheter during labour increase risk of infection? . The Journal of Maternal-Fetal \& Neonatal Medicine 2011 June 7 [Epub ahead of print].

\section{Chia 1993 \{published and unpublished data\}}

Chia YT, Arulkumaran S, Soon SB, Norshida S, Ratnam SS. Induction of labour: does internal tocography result in better obstetric outcome than external tocography. Australian \& New Zealand Journal of Obstetrics \& Gynaecology 1993;33:159-61.

Chua 1990 \{published data only\}

* Chua S, Kurup A, Arulkumaran S, Ratnam SS. Augmentation of labor: does internal tocography result in better obstetric outcome than external tocography?. Obstetrics and Gynecology 1990;76:164-7.

Chua S, Kurup A, Arulkumaran S, Ratnam SS. Augmentation of labour: internal tocography does not result in better obstetric outcome than external tocography. International Journal of Gynaecology and Obstetrics 1991;36 Suppl:368.

\section{References to studies excluded from this review}

\section{Arulkumaran 1991 \{published data only\}}

Arulkumaran S, Yang M, Tien CY, Ratnam SS. Reliability of intrauterine pressure measurements. Obstetrics and Gynecology 1991;78(5):800-2.

Bsat 1992 \{published data only\}

Bsat F, Warsof S. Comparison of extraovular and intraovular uterine contraction monitoring. American Journal of Obstetrics and Gynecology 1991;164:252.

* Bsat FA, Warsof S. Extraovular and intraovular uterine contraction monitoring: a comparison. Journal of Reproductive Medicine 1992;37(9):813-6.

Chua 1992 \{published data only\}

Chua S, Arulkumaran S, Yang M, Ratnam SS, Steer PJ. The accuracy of catheter-tip pressure transducers for the measurement of intrauterine pressure in labour. British Journal of Obstetrics and Gynaecology 1992;99:186-9.
Chua 1998 \{published data only\}

Chua S, Lee M, Vanaja K, Chong YS, Nordstrom L, Arulkumaran $\mathrm{S}$. The reliability of catheter-tip transducers for the measurement of intrauterine pressure in the third stage of labour. British Journal of Obstetrics and Gynaecology 1998;105:352-6.

Lemus 1997 \{published data only\}

Lemus J, Balducci J, Atlas R, Klasko S. The use of intrauterine pressure catheters in active management of labor. American Journal of Obstetrics and Gynecology 1997; 176(1 Pt 2):S142.

Panayotopoulos 1998 \{published data only\} Panayotopoulos N, Salamalekis E, Vitoratos N, Loghis C, Kassanos D. Monitoring of uterine activity in cases of labor augmentation, and neonatal outcome. Prenatal and Neonatal Medicine 1998;3:464-7.

Sciscione 2005 \{published data only\}

Sciscione A, Rhee A, Duhl A, Pollock M, Hoffman M, Colmorgen G. Intrauterine pressure catheters (IUPC) and the risk of extra-ovular placement and resultant placental separation [abstract]. American Journal of Obstetrics and Gynecology 2001;185(6 Suppl):S91.

Sciscione A, Rhee A, Duhl A, Pollock M, Maas B, Manley $\mathrm{J}$, et al.A randomized prospective trial of two types of intrauterine pressure catheters and the rate of extra-ovular placement. American Journal of Obstetrics and Gynecology 2000;182(1 Pt 2):S154.

* Sciscione AC, Duhl A, Pollock MA, Hoffman MK, Rhee A, Colmorgen GH. Extramembranous placement of an aircoupled vs. transducer-tipped intrauterine pressure catheter. Journal of Reproductive Medicine 2005;50(8):578-84.

\section{Additional references}

\section{ACOG 2009}

American College of Obstetrics and Gynecology Committee on Practice Bulletins. Dystocia and Augmentation of Labor. ACOG Practice Bulletin Number 49. ACOG, 2009.

Alfirevic 2009

Alfirevic Z, Kelly A, Dowswell T. Intravenous oxytocin alone for cervical ripening and induction of labour. Cochrane Database of Systematic Reviews 2009, Issue 4. [DOI: 10.1002/14651858.CD003246.pub2]

Bakker 2008

Bakker PC, Zikkenheimer M, van Geijn HP. The quality of intrapartum uterine activity monitoring. Journal of Perinatal Medicine 2008;36(3):197-201.

Chan 1973

Chan WH, Paul RH, Toews J. Intrapartum fetal monitoring: maternal and fetal morbidity and perinatal mortality. Obstetrics and Gynecology 1973;41:7-13.

Dale 1906

Dale HH. On some physiological actions of ergot. Journal of Physiology 1906;34(3):163-206. 
Egger 1997

Egger M, Davey Smith G, Schneider M, Minder C. Bias in meta-analysis detected by a simple, graphical test. $B M J$ 1997;315(7109):629-34.

Handwerker 1995

Handwerker SM, Selick AM. Placental abruption after insertion of catheter tip intrauterine pressure transducers: a report of four cases. Journal of Reproductive Medicine 1995; 40(12):845-9.

\section{Harbison 2010}

Harbison L, Bell L. Anaphylactoid syndrome after intrauterine pressure catheter placement. Obstetrics and Gynecology 2010;115(2 Pt 2):407-8.

\section{Harbord 2006}

Harbord RM, Egger M, Sterne JA. A modified test for small-study effects in meta-analyses of controlled trials with binary endpoints. Statistics in Medicine 2006;25(20): 3443-57.

\section{Higgins 2011}

Higgins JPT, Green S, editors. Cochrane Handbook for Systematic Reviews of Interventions Version 5.1.0 [updated March 2011]. The Cochrane Collaboration, 2011. Available from www.cochrane-handbook.org.

\section{Howarth 2001}

Howarth GR, Botha DJ. Amniotomy plus intravenous oxytocin for induction of labour. Cochrane Database of Systematic Reviews 2001, Issue 3. [DOI: 10.1002/ 14651858.CD003250]

\section{Land 1983}

Land H, Grez M, Ruppert S, Schmale H, Rehbein M, Richter D, et al.Deduced amino acid sequence from the bovine oxytocin-neurophysin I precursor cDNA. Nature 1983;302:342-4.

\section{Lind 1998}

Lind BK. The frequency of extramembranous placement of intrauterine pressure catheters. Primary Care Update for Ob/ Gyns 1998;5(4):185.

\section{Lind 1999}

Lind BK. Complications caused by extramembranous placement of intrauterine pressure catheters. American Journal of Obstetrics and Gynecology 1999;180(4):1034-5.

\section{MacKenzie 2006}

MacKenzie IZ. Induction of labour at the start of the new millennium. Reproduction 2006;131(6):989-98.

\section{Matsuo 2008}

Matsuo K, Lynch MA, Kopelman JN, Atlas RO. Anaphylactoid syndrome of pregnancy immediately after intrauterine pressure catheter placement. American Journal of Obstetrics and Gynecology 2008;198(2):e8-e9.

\section{Osterman 2011}

Osterman MJ, Martin JA, Mathews TJ, Hamilton BE. Expanded data from the new birth certificate. National Vital Statistics Reports 2011;59(7):1-28. [PUBMED: 21848043]

\section{RevMan 2011}

The Nordic Cochrane Centre, The Cochrane Collaboration. Review Manager (RevMan). 5.1. Copenhagen: The Nordic Cochrane Centre, The Cochrane Collaboration, 2011.

\section{Rodriquez 1989}

Rodriquez MH, Masaki DI, Phelan JP, Diaz FG. Uterine rupture: are intrauterine pressure catheters useful in the diagnosis?. American Journal of Obstetrics and Gynecology 1989;161:666-9.

\section{Smith 2006}

Smith JG, Merrill DC. Oxytocin for induction of labor. Clinical Obstetrics and Gynecology 2006;49(3):594-608.

\section{Soper 1989}

Soper DE, Mayhall CG, Dalton HP. Risk factors for intraamniotic infection: a prospective epidemiologic study. American Journal of Obstetrics and Gynecology 1989;161(3): 562-6.

\section{Soper 1996}

Soper DE, Mayhall CG, Froggatt JW. Characterization and control of intraamniotic infection in an urban teaching hospital. American Journal of Obstetrics and Gynecology 1996;175(2):304-9.

\section{Trudinger 1978}

Trudinger BJ, Pryse-Davies J. Fetal hazards of the intrauterine pressure catheter: five case reports. British Journal Obstetrics and Gynaecology 1978;85:573-4.

\section{van Halem 2011}

van Halem K, Bakker JJH, Verhoeven CJ, Papatsonis DN, van Oudgaarden ED, Janssen PF, et al.Does use of an intrauterine catheter during labour increase risk of infection?. Journal of Maternal-Fetal \& Neonatal Medicine 2011 June 7 [Epub ahead of print].

\section{Wilmink 2008}

Wilmink FA, Wilms FF, Heydanus R, Mol BW, Papatsonis DN. Fetal complications after placement of an intrauterine pressure catheter: a report of two cases and review of the literature. Journal of Maternal-Fetal \& Neonatal Medicine 2008;21(12):880-3.

* Indicates the major publication for the study 


\section{CHARACTERISTICS OF STUDIES}

\section{Characteristics of included studies [ordered by year of study]}

\section{Chua 1990}

\begin{tabular}{|c|c|}
\hline Methods & Randomised controlled trial. \\
\hline Participants & $\begin{array}{l}250 \text { women with spontaneous onset of labour, slow progress and the indication for } \\
\text { augmentation with oxytocin }\end{array}$ \\
\hline Interventions & $\begin{array}{l}\text { Intervention: } 125 \text { women were allocated to internal tocodynamometry } \\
\text { Control: } 125 \text { women were allocated to external tocodynamometry }\end{array}$ \\
\hline Outcomes & $\begin{array}{l}\text { Length of labour. } \\
\text { Dose of oxytocin. } \\
\text { Rate of caesarean section. } \\
\text { Vaginal instrumental deliveries. } \\
\text { Apgar score }<4 \text { at } 1 \text { minute. } \\
\text { Apgar score }<6 \text { at } 5 \text { minutes. } \\
\text { Neonatal admission for asphyxia. } \\
\text { Birthweight. } \\
\text { The number of times the dose of oxytocin had to be reduced for reasons of hyperstim- } \\
\text { ulation (i.e. more than seven contractions in } 15 \text { minutes) or fetal heart rate changes }\end{array}$ \\
\hline Notes & $\begin{array}{l}\text { Women with a caesarean section were likely to be excluded (personal communication } \\
\text { Prof Arulkumaran) } \\
\text { No primary outcome defined. } \\
\text { Sources of funding not stated. }\end{array}$ \\
\hline
\end{tabular}

Risk of bias

\begin{tabular}{l|l|l}
\hline Bias & Authors judgement & Support for judgement \\
\hline $\begin{array}{l}\text { Random sequence generation (selection } \\
\text { bias) }\end{array}$ & Low risk & $\begin{array}{l}\text { Quote: "Randomly assigned using a random number } \\
\text { table". }\end{array}$ \\
\hline $\begin{array}{l}\text { Allocation concealment (selection bias) } \\
\begin{array}{l}\text { Blinding of participants and personnel } \\
\text { (performance bias) } \\
\text { All outcomes }\end{array}\end{array}$ & Unclear risk & No report of method of concealment. \\
\hline $\begin{array}{l}\text { Blinding of outcome assessment (detection } \\
\text { bias) } \\
\text { All outcomes }\end{array}$ & Unclear risk & $\begin{array}{l}\text { Not reported but due to the kind of intervention we } \\
\text { expect no blinding }\end{array}$ \\
\hline
\end{tabular}

Incomplete outcome data (attrition bias) Unclear risk All outcomes

Not reported, no crossover reported so we assume the participants were analysed in the group they were assigned to 
Chua 1990 (Continued)

\begin{tabular}{lll}
\hline Selective reporting (reporting bias) & Low risk & No missing relevant outcomes. \\
\hline Other bias & Low risk & None \\
\hline
\end{tabular}

Chia 1993

\begin{tabular}{|c|c|}
\hline Methods & Randomised controlled trial. \\
\hline Participants & 239 women with induced labour. \\
\hline Interventions & $\begin{array}{l}\text { Intervention: } 118 \text { women were allocated to internal tocodynamometry } \\
\text { Control: } 121 \text { women were allocated to external tocodynamometry }\end{array}$ \\
\hline Outcomes & $\begin{array}{l}\text { Length of labour. } \\
\text { Dose of oxytocin. } \\
\text { Rate of caesarean section. } \\
\text { Vaginal instrumental deliveries. } \\
\text { Apgar score }<5 \text { at } 1 \text { minute. } \\
\text { Apgar score }<7 \text { at } 5 \text { minutes. } \\
\text { Cord arterial blood } \mathrm{pH}<7.16 \text {. } \\
\text { Neonatal admission for asphyxia. } \\
\text { Birthweight. } \\
\text { The number of times reduction in oxytocin was needed for hyperstimulation or car- } \\
\text { diotocographic changes. Hyperstimulation was defined as a contraction frequency }>7 \\
\text { contractions in } 15 \text { minutes or a rise in baseline tone between contractions for more than } \\
3 \text { minutes }\end{array}$ \\
\hline Notes & $\begin{array}{l}\text { Women with a caesarean section were likely to be excluded (personal communication } \\
\text { Prof Arulkumaran) } \\
\text { No primary outcome defined. } \\
\text { Sources of funding not stated. } \\
\text { Calculation error in percentages in table } 3 \text {, arterial blood pH }\end{array}$ \\
\hline
\end{tabular}

\section{Risk of bias}

\begin{tabular}{lll}
\hline Bias & Authors' judgement & Support for judgement \\
\hline $\begin{array}{l}\text { Random sequence generation (selection } \\
\text { bias) }\end{array}$ & Low risk & $\begin{array}{l}\text { Quote: "Randomly assigned using a random number } \\
\text { table". }\end{array}$ \\
\hline $\begin{array}{l}\text { Allocation concealment (selection bias) } \\
\begin{array}{l}\text { Blinding of participants and personnel } \\
\text { (performance bias) } \\
\text { All outcomes }\end{array}\end{array}$ & Unclear risk & No report of method of concealment. \\
\hline
\end{tabular}


Chia 1993 (Continued)

\begin{tabular}{l|l|l}
\hline $\begin{array}{l}\text { Blinding of outcome assessment (detection } \\
\text { bias) } \\
\text { All outcomes }\end{array}$ & Unclear risk & Not reported. \\
\hline $\begin{array}{l}\text { Incomplete outcome data (attrition bias) } \\
\text { All outcomes }\end{array}$ & Unclear risk & $\begin{array}{l}\text { Not reported, no crossover reported so we assume the } \\
\text { participants were analysed in the group they were as- } \\
\text { signed to }\end{array}$ \\
\hline Selective reporting (reporting bias) & Low risk & No missing relevant outcomes. \\
\hline Other bias & Low risk & None \\
\hline
\end{tabular}

Bakker 2010

\begin{tabular}{ll}
\hline Methods & Randomised controlled trial. \\
\hline Participants & $\begin{array}{l}1456 \text { women with a singleton pregnancy and gestational age beyond } 36 \text { weeks, a child } \\
\text { in cephalic position and an indication for either induction or augmentation of labour } \\
\text { with intravenous oxytocin }\end{array}$ \\
\hline Interventions & $\begin{array}{l}\text { Intervention: } 734 \text { women were allocated to internal tocodynamometry } \\
\text { Control: } 722 \text { women were allocated to external internal tocodynamometry }\end{array}$ \\
\hline Outcomes & $\begin{array}{l}\text { Operative deliveries, including both caesarean sections and instrumental vaginal deliv- } \\
\text { eries } \\
\text { Use of antibiotics during labour. } \\
\text { Length of labour. } \\
\text { Adverse neonatal outcomes (defined as any of the following: an Apgar score at } 5 \text { minutes } \\
\text { of less than } 7, \text { umbilical artery pH of less than } 7.05, \text { and neonatal hospital stay of longer } \\
\text { than } 48 \text { hours) }\end{array}$ \\
\hline Notes & \begin{tabular}{l} 
Follow-up trial van Halem 2011. \\
\hline
\end{tabular}
\end{tabular}

\section{Risk of bias}

\begin{tabular}{lll}
\hline Bias & Authors' judgement & Support for judgement \\
\hline $\begin{array}{l}\text { Random sequence generation (selection } \\
\text { bias) }\end{array}$ & Low risk & $\begin{array}{l}\text { Quote: "Randomisation was done by a computer pro- } \\
\text { gram". }\end{array}$ \\
\hline
\end{tabular}

Allocation was concealed because of the computerized method of randomisation with use of a minimisation method

Sequence was generated at a central location in the department of epidemiology 
Bakker 2010 (Continued)

Blinding of participants and personnel Unclear risk (performance bias)

All outcomes

Blinding of outcome assessment (detection Unclear risk bias)

All outcomes

Incomplete outcome data (attrition bias) Low risk All outcomes
Due to the intervention no blinding. However influence of this knowledge by patients or personnel on the outcomes is highly unlikely

No blinding in the randomised controlled trial, in the follow-up study of van Halem 2011 the assessor was blinded for the allocation

No missing outcome data, analysis was performed according to the intention-to-treat principle

For the outcome "infection up to three weeks postpartum" in the follow-up report of van Halem, women with an indication for prophylactic antibiotic during labour for known positive GBS status, heart disease, or other reasons for prophylaxis were excluded from the data set of the Bakker trial

Selective reporting (reporting bias) Low risk

Unclear risk
The protocol of the study was published in the Dutch trials register before start of inclusion. No difference between protocol and publication was found In contrast with the two former trials hyperstimulation was no outcome measure. Selective reporting of hyperstimulation would influence neonatal outcome therefore this is not likely

$72 \%$ of eligible patients were not counselled for the study.

\section{Characteristics of excluded studies [ordered by study ID]}

\begin{tabular}{ll}
\hline Study & Reason for exclusion \\
\hline Arulkumaran 1991 & No comparison. \\
\hline Bsat 1992 & No comparison between extrauterine and intrauterine registration \\
\hline Chua 1992 & No randomised comparison. \\
\hline Chua 1998 & No randomised comparison. \\
\hline Lemus 1997 & No use of oxytocin. \\
\hline Panayotopoulos 1998 & $\begin{array}{l}\text { Quasi-RCT; answers the research question but was excluded because the randomisation method was not } \\
\text { valid }\end{array}$
\end{tabular}

Internal versus external tocodynamometry during induced or augmented labour (Review) 
(Continued)

Sciscione 2005

No randomised comparison.

Internal versus external tocodynamometry during induced or augmented labour (Review)

Copyright $\odot 2012$ The Cochrane Collaboration. Published by John Wiley \& Sons, Ltd. 
DATA AND ANALYSES

Comparison 1. Monitoring of contractions with internal tocodynamometry compared to external tocodynamometry

\begin{tabular}{|c|c|c|c|c|}
\hline Outcome or subgroup title & $\begin{array}{l}\text { No. of } \\
\text { studies }\end{array}$ & $\begin{array}{c}\text { No. of } \\
\text { participants }\end{array}$ & Statistical method & Effect size \\
\hline 1 Uterine rupture & 3 & 1945 & Risk Ratio (M-H, Fixed, 95\% CI) & $0.0[0.0,0.0]$ \\
\hline 2 Hyperstimulation & 2 & 489 & Risk Ratio (M-H, Fixed, 95\% CI) & $1.21[0.78,1.88]$ \\
\hline $\begin{array}{l}3 \text { Apgar score less than seven at } \\
\text { five minutes }\end{array}$ & 3 & 1945 & Risk Ratio (M-H, Fixed, 95\% CI) & $1.78[0.83,3.83]$ \\
\hline 4 Umbilical artery $\mathrm{pH}<7.15$ & 1 & 1456 & Risk Ratio (M-H, Fixed, 95\% CI) & $1.31[0.95,1.79]$ \\
\hline 5 Umbilical artery $\mathrm{pH}<7.05$ & 1 & 1456 & Risk Ratio (M-H, Fixed, 95\% CI) & $0.90[0.40,2.03]$ \\
\hline 6 Umbilical artery $\mathrm{pH}<7.16$ & 1 & 239 & Risk Ratio (M-H, Fixed, 95\% CI) & $1.23[0.39,3.92]$ \\
\hline $\begin{array}{l}7 \text { Admission to neonatal intensive } \\
\text { care }\end{array}$ & 2 & 489 & Risk Ratio (M-H, Fixed, 95\% CI) & $0.34[0.07,1.67]$ \\
\hline 8 Neonatal admission $>48$ hours & 1 & 1456 & Risk Ratio (M-H, Fixed, 95\% CI) & $0.92[0.71,1.20]$ \\
\hline 9 Perinatal mortality & 3 & 1945 & Risk Ratio (M-H, Fixed, 95\% CI) & $0.0[0.0,0.0]$ \\
\hline $\begin{array}{l}10 \text { Serious maternal outcomes } \\
\text { (defined as death, coma, cardiac } \\
\text { arrest, respiratory arrest, use } \\
\text { of a mechanical ventilator, } \\
\text { admission to intensive care } \\
\text { unit) }\end{array}$ & 3 & 1945 & Risk Ratio (M-H, Fixed, 95\% CI) & $0.0[0.0,0.0]$ \\
\hline 11 Instrumental delivery & 3 & 1945 & Risk Ratio (M-H, Fixed, 95\% CI) & $1.05[0.91,1.21]$ \\
\hline 11.1 Induced labour & 2 & 1195 & Risk Ratio (M-H, Fixed, 95\% CI) & $0.91[0.75,1.10]$ \\
\hline 11.2 Augmented labour & 2 & 750 & Risk Ratio (M-H, Fixed, 95\% CI) & $1.25[1.02,1.53]$ \\
\hline 12 Instrumental vaginal delivery & 3 & 1945 & Risk Ratio (M-H, Fixed, 95\% CI) & $1.06[0.85,1.32]$ \\
\hline 12.1 Induced labour & 2 & 1195 & Risk Ratio (M-H, Fixed, 95\% CI) & $0.90[0.66,1.24]$ \\
\hline 12.2 Augmented labour & 2 & 750 & Risk Ratio (M-H, Fixed, 95\% CI) & $1.25[0.91,1.73]$ \\
\hline 13 Caesarean section & 3 & 1945 & Risk Ratio (M-H, Fixed, 95\% CI) & $1.04[0.85,1.29]$ \\
\hline 13.1 Induced labour & 2 & 1195 & Risk Ratio (M-H, Fixed, 95\% CI) & $0.91[0.68,1.21]$ \\
\hline 13.2 Augmented labour & 2 & 750 & Risk Ratio (M-H, Fixed, 95\% CI) & $1.25[0.91,1.71]$ \\
\hline 14 Mean time to delivery & 1 & 1456 & Mean Difference (IV, Fixed, 95\% CI) & $\begin{array}{l}-15.60[-40.99,9 . \\
79]\end{array}$ \\
\hline 14.1 induced labour & 1 & 956 & Mean Difference (IV, Fixed, 95\% CI) & $\begin{array}{l}-25.78[-58.57,7 . \\
01]\end{array}$ \\
\hline 14.2 Augmented labour & 1 & 500 & Mean Difference (IV, Fixed, 95\% CI) & $\begin{array}{l}-0.35[-40.47,39 . \\
77]\end{array}$ \\
\hline 15 Placental or fetal vessel damage & 3 & 1945 & Risk Ratio (M-H, Fixed, 95\% CI) & $0.0[0.0,0.0]$ \\
\hline $\begin{array}{l}16 \text { Indication of infection up to } \\
\text { three weeks postpartum in } \\
\text { mother or child }\end{array}$ & 1 & 1435 & Risk Ratio (M-H, Fixed, 95\% CI) & $0.84[0.61,1.16]$ \\
\hline $\begin{array}{l}17 \text { Signs intrauterine infection } \\
\text { during labor }\end{array}$ & 1 & 1456 & Risk Ratio (M-H, Fixed, 95\% CI) & $0.69[0.44,1.08]$ \\
\hline
\end{tabular}

Internal versus external tocodynamometry during induced or augmented labour (Review) 
Analysis I.I. Comparison I Monitoring of contractions with internal tocodynamometry compared to external tocodynamometry, Outcome I Uterine rupture.

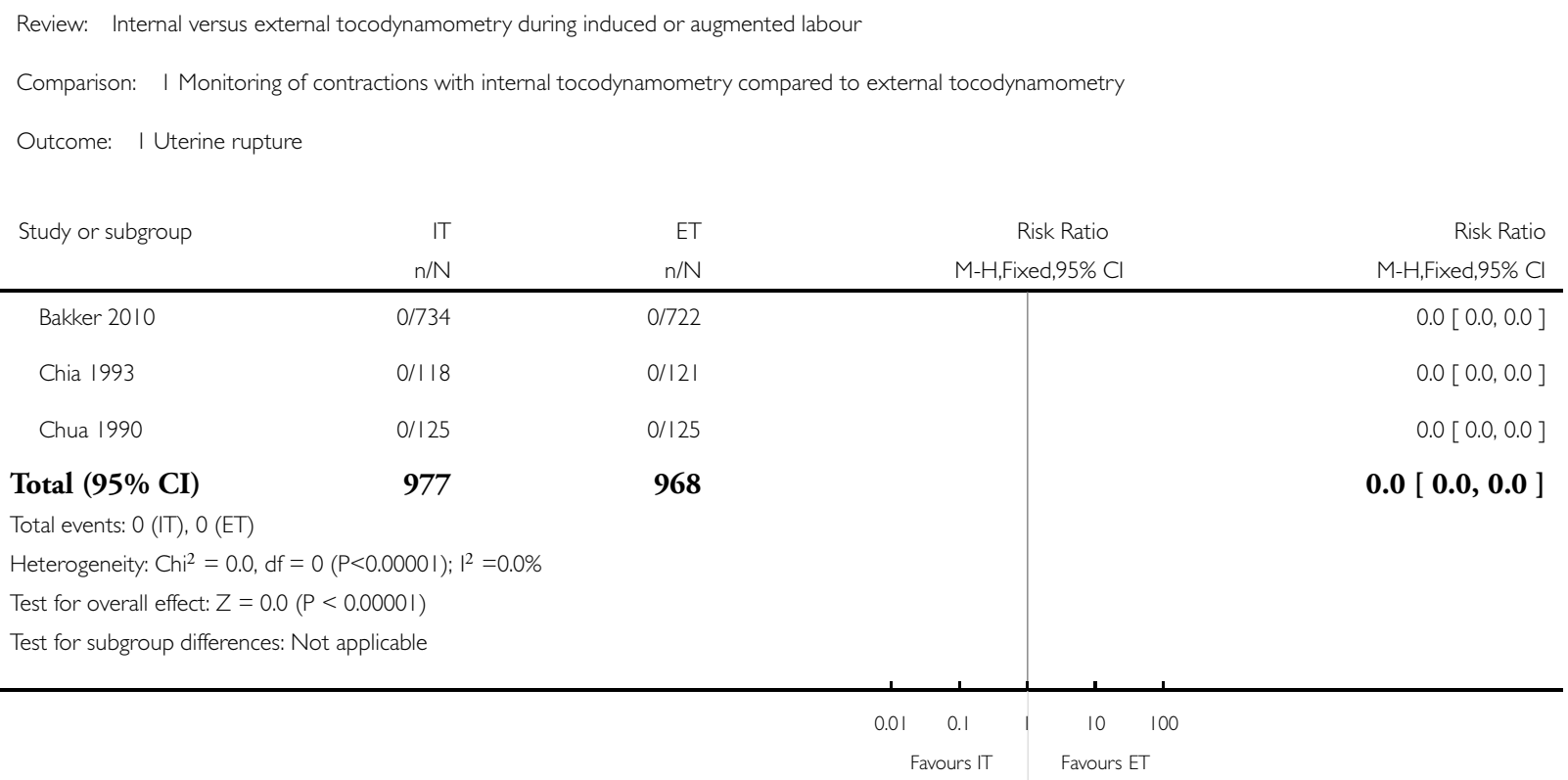


Analysis I.2. Comparison I Monitoring of contractions with internal tocodynamometry compared to external tocodynamometry, Outcome 2 Hyperstimulation.

Review: Internal versus external tocodynamometry during induced or augmented labour

Comparison: I Monitoring of contractions with internal tocodynamometry compared to external tocodynamometry

Outcome: 2 Hyperstimulation

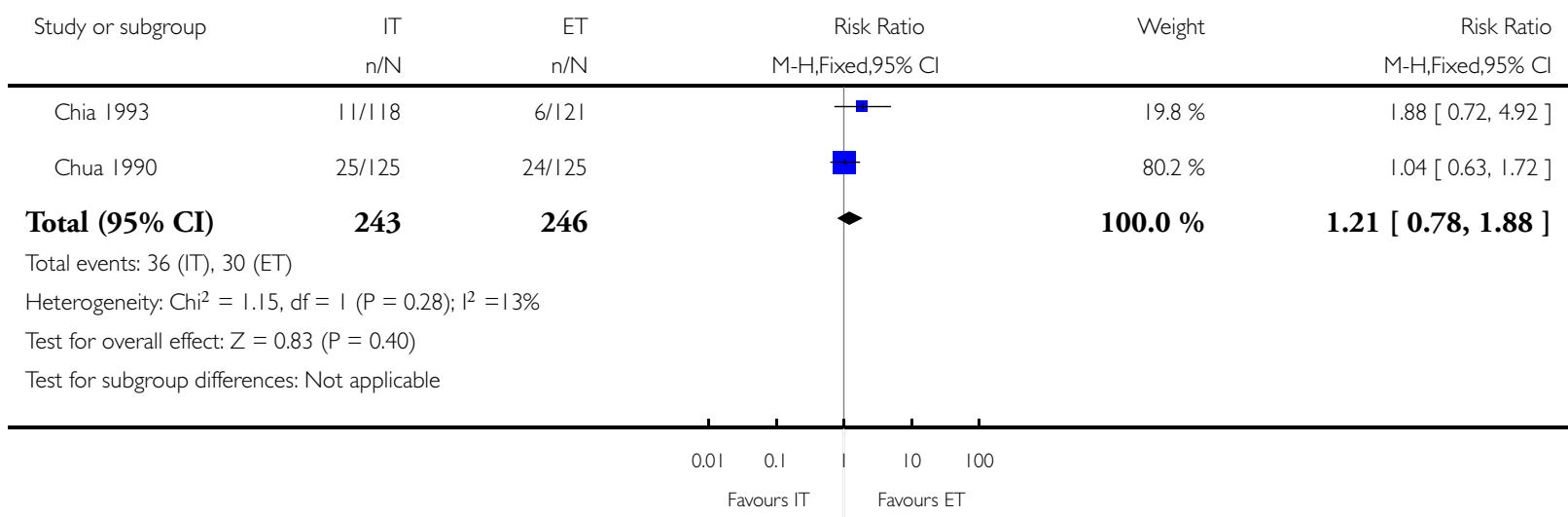


Analysis I.3. Comparison I Monitoring of contractions with internal tocodynamometry compared to external tocodynamometry, Outcome 3 Apgar score less than seven at five minutes.

Review: Internal versus external tocodynamometry during induced or augmented labour

Comparison: I Monitoring of contractions with internal tocodynamometry compared to external tocodynamometry

Outcome: 3 Apgar score less than seven at five minutes

\begin{tabular}{|c|c|c|c|c|c|}
\hline \multirow[t]{2}{*}{ Study or subgroup } & IT & ET & Risk Ratio & Weight & Risk Ratio \\
\hline & $\mathrm{n} / \mathrm{N}$ & $\mathrm{n} / \mathrm{N}$ & M-H,Fixed,95\% Cl & & M-H,Fixed,95\% Cl \\
\hline Bakker 2010 & $16 / 734$ & $8 / 722$ & & $80.2 \%$ & $1.97[0.85,4.57]$ \\
\hline Chia 1993 & $1 / 118$ & $|/| 2 \mid$ & & $9.8 \%$ & $1.03[0.06,16.20]$ \\
\hline Chua 1990 & $1 / 125$ & $1 / 125$ & & $9.9 \%$ & $1.00[0.06, \mid 5.81]$ \\
\hline
\end{tabular}

Total (95\% CI)

977

968

$100.0 \%$

$1.78[0.83,3.83]$

Total events: 18 (IT), 10 (ET)

Heterogeneity: Chi $^{2}=0.38, \mathrm{df}=2(\mathrm{P}=0.83) ; \mathrm{I}^{2}=0.0 \%$

Test for overall effect: $Z=1.47(P=0.14)$

Test for subgroup differences: Not applicable

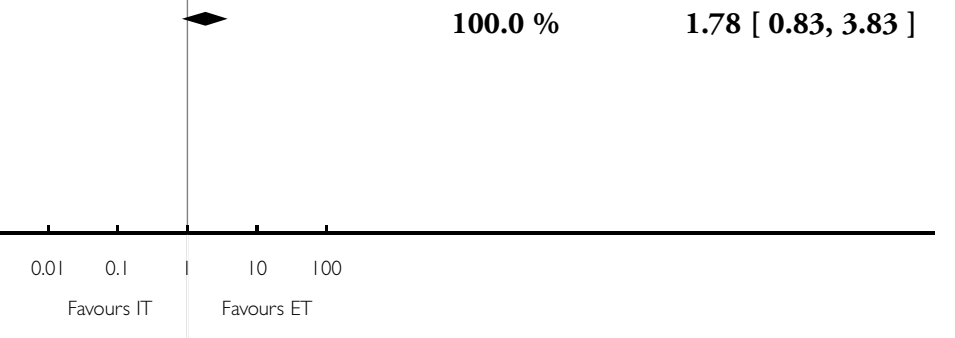

Analysis I.4. Comparison I Monitoring of contractions with internal tocodynamometry compared to external tocodynamometry, Outcome 4 Umbilical artery $\mathrm{pH}<7.15$.

Review: Internal versus external tocodynamometry during induced or augmented labour

Comparison: I Monitoring of contractions with internal tocodynamometry compared to external tocodynamometry

Outcome: 4 Umbilical artery $\mathrm{pH}<7.15$

\begin{tabular}{|c|c|c|c|c|c|c|c|c|}
\hline \multirow[t]{2}{*}{ Study or subgroup } & IT & ET & \multicolumn{4}{|c|}{ Risk Ratio } & Weight & Risk Ratio \\
\hline & $\mathrm{n} / \mathrm{N}$ & $\mathrm{n} / \mathrm{N}$ & \multicolumn{4}{|c|}{ M-H,Fixed,95\% Cl } & & M-H,Fixed,95\% Cl \\
\hline Bakker 2010 & $81 / 734$ & $61 / 722$ & & & & & $100.0 \%$ & $1.31[0.95,1.79]$ \\
\hline Total $(95 \%$ CI $)$ & 734 & 722 & & & $\bullet$ & & $100.0 \%$ & $1.31[0.95,1.79]$ \\
\hline \multicolumn{9}{|c|}{ Total events: 8I (IT), 6I (ET) } \\
\hline \multicolumn{9}{|c|}{ Heterogeneity: not applicable } \\
\hline \multicolumn{9}{|c|}{ Test for overall effect: $Z=1.66(P=0.098)$} \\
\hline \multicolumn{9}{|c|}{ Test for subgroup differences: Not applicable } \\
\hline & & & 0.01 & 0.1 & 10 & 100 & & \\
\hline \multicolumn{9}{|c|}{ Favours IT } \\
\hline
\end{tabular}

Internal versus external tocodynamometry during induced or augmented labour (Review)

Copyright $\Subset 2012$ The Cochrane Collaboration. Published by John Wiley \& Sons, Ltd. 


\section{Analysis I.5. Comparison I Monitoring of contractions with internal tocodynamometry compared to}

external tocodynamometry, Outcome 5 Umbilical artery $\mathrm{pH}<7.05$.

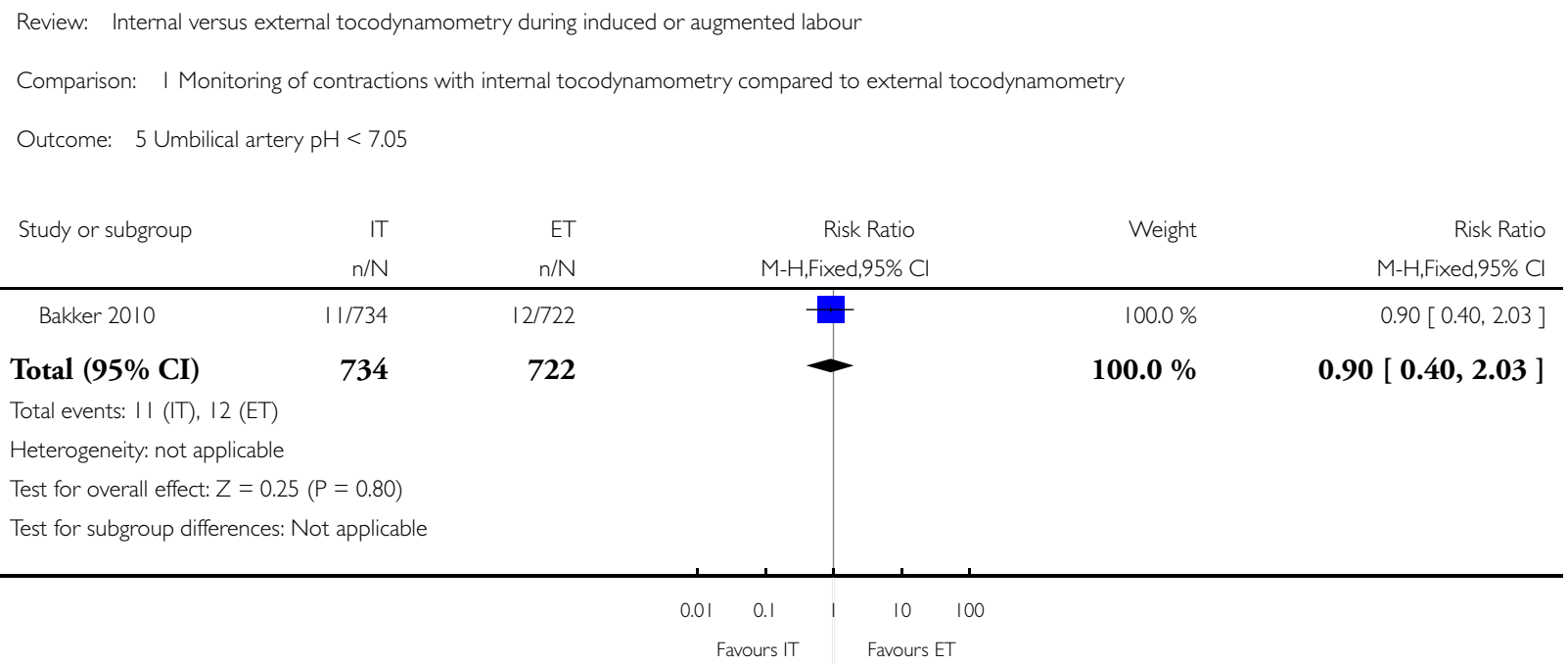


Analysis I.6. Comparison I Monitoring of contractions with internal tocodynamometry compared to external tocodynamometry, Outcome 6 Umbilical artery $\mathrm{pH}<7.16$.

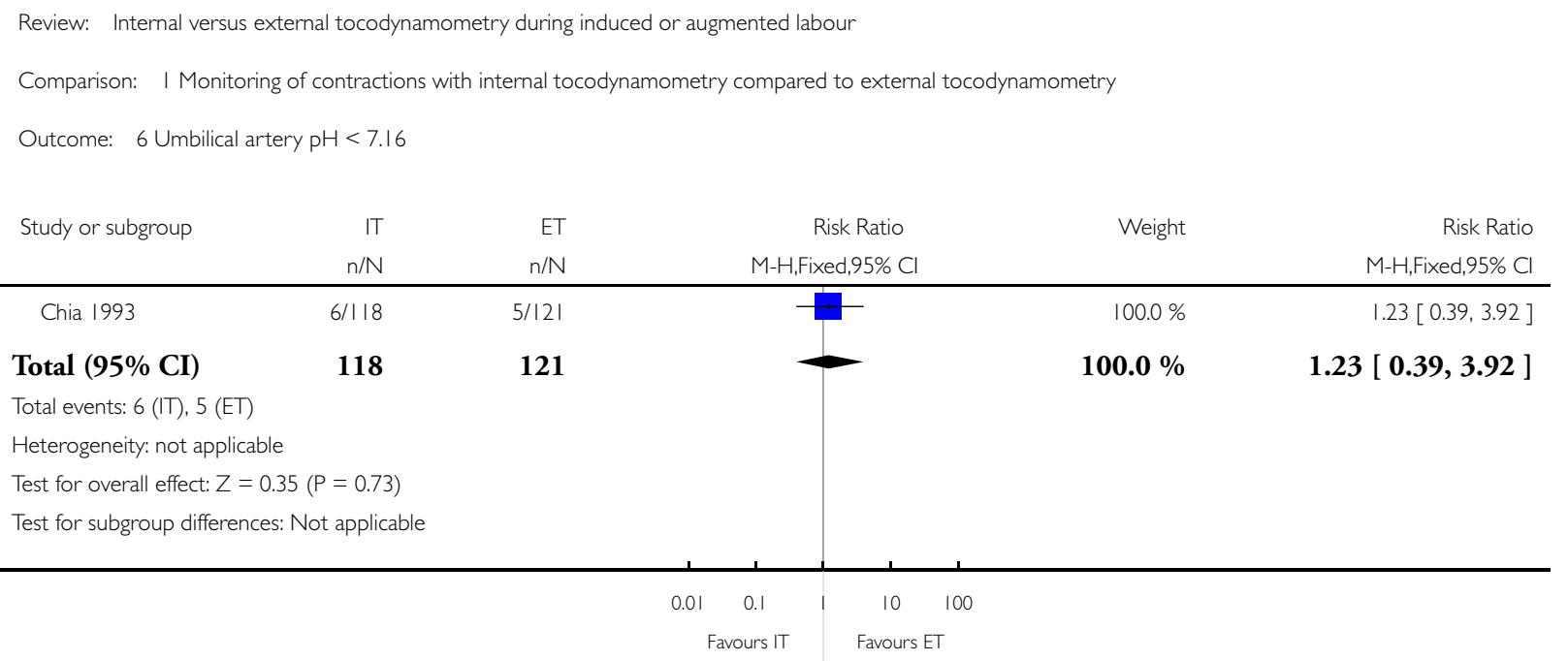

Analysis I.7. Comparison I Monitoring of contractions with internal tocodynamometry compared to external tocodynamometry, Outcome 7 Admission to neonatal intensive care.

Review: Internal versus external tocodynamometry during induced or augmented labour

Comparison: I Monitoring of contractions with internal tocodynamometry compared to external tocodynamometry

Outcome: 7 Admission to neonatal intensive care

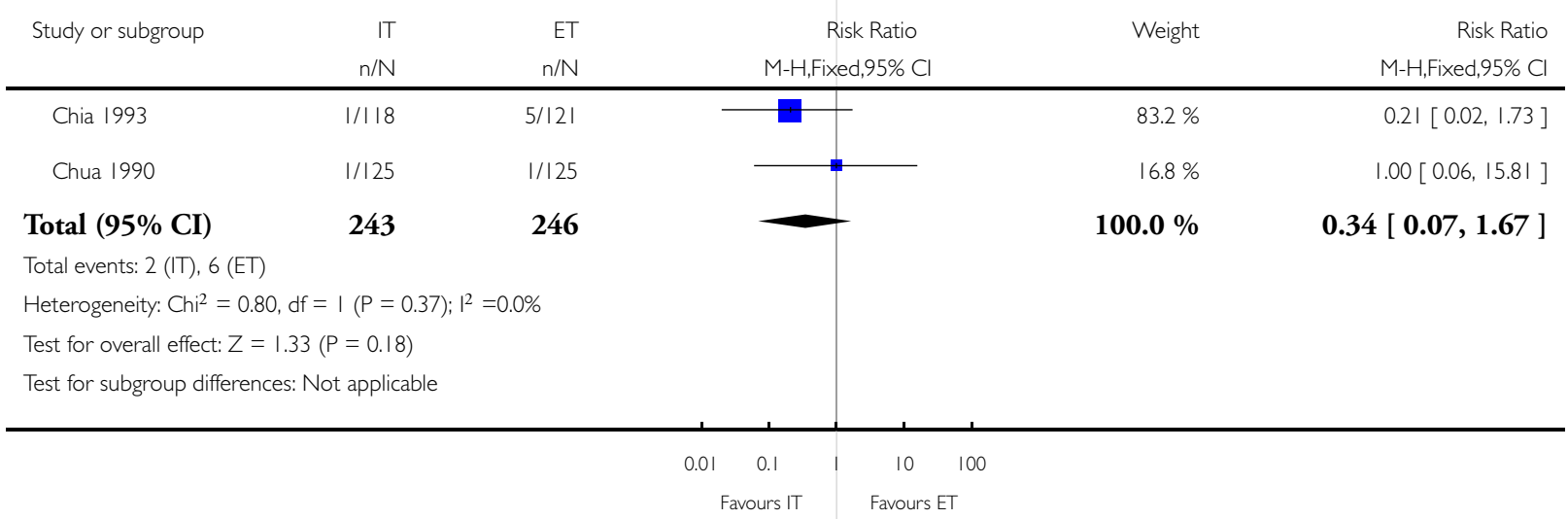


Analysis I.8. Comparison I Monitoring of contractions with internal tocodynamometry compared to external tocodynamometry, Outcome 8 Neonatal admission $>48$ hours.

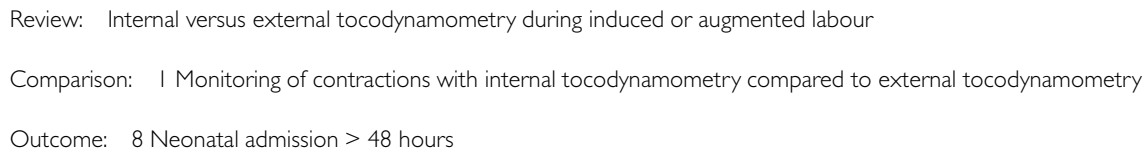

\begin{tabular}{ccccc} 
Study or subgroup & IT & ET & Risk Ratio & Risk Ratio \\
& $\mathrm{n} / \mathrm{N}$ & $\mathrm{n} / \mathrm{N}$ & $\mathrm{M}-\mathrm{H}$, Fixed,95\% Cl & Weight \\
\hline Bakker 2010 & $93 / 734$ & $99 / 722$ & $100.0 \%$
\end{tabular}

Total (95\% CI)

Analysis 1.9. Comparison I Monitoring of contractions with internal tocodynamometry compared to external tocodynamometry, Outcome 9 Perinatal mortality.

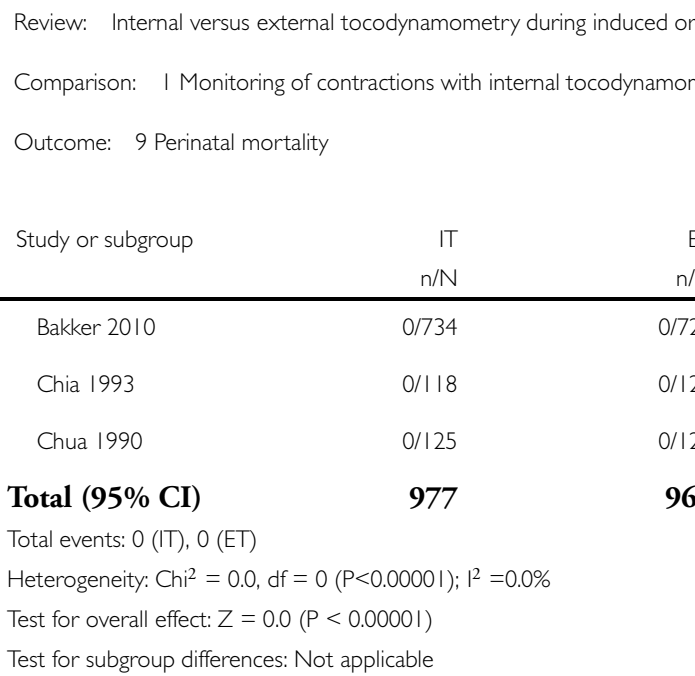

Test for subgroup differences: Not applicable

\begin{tabular}{rrr}
$E T$ & Risk Ratio & Risk Ratio \\
$n / N$ & M-H,Fixed,95\% Cl & M-H,Fixed,95\% Cl \\
\hline $0 / 722$ & & $0.0[0.0,0.0]$ \\
$0 / 121$ & & $0.0[0.0,0.0]$ \\
$0 / 125$ & & $0.0[0.0,0.0]$
\end{tabular}

968

$0.0[0.0,0.0]$ 
Analysis I.10. Comparison I Monitoring of contractions with internal tocodynamometry compared to external tocodynamometry, Outcome 10 Serious maternal outcomes (defined as death, coma, cardiac arrest, respiratory arrest, use of a mechanical ventilator, admission to intensive care unit).

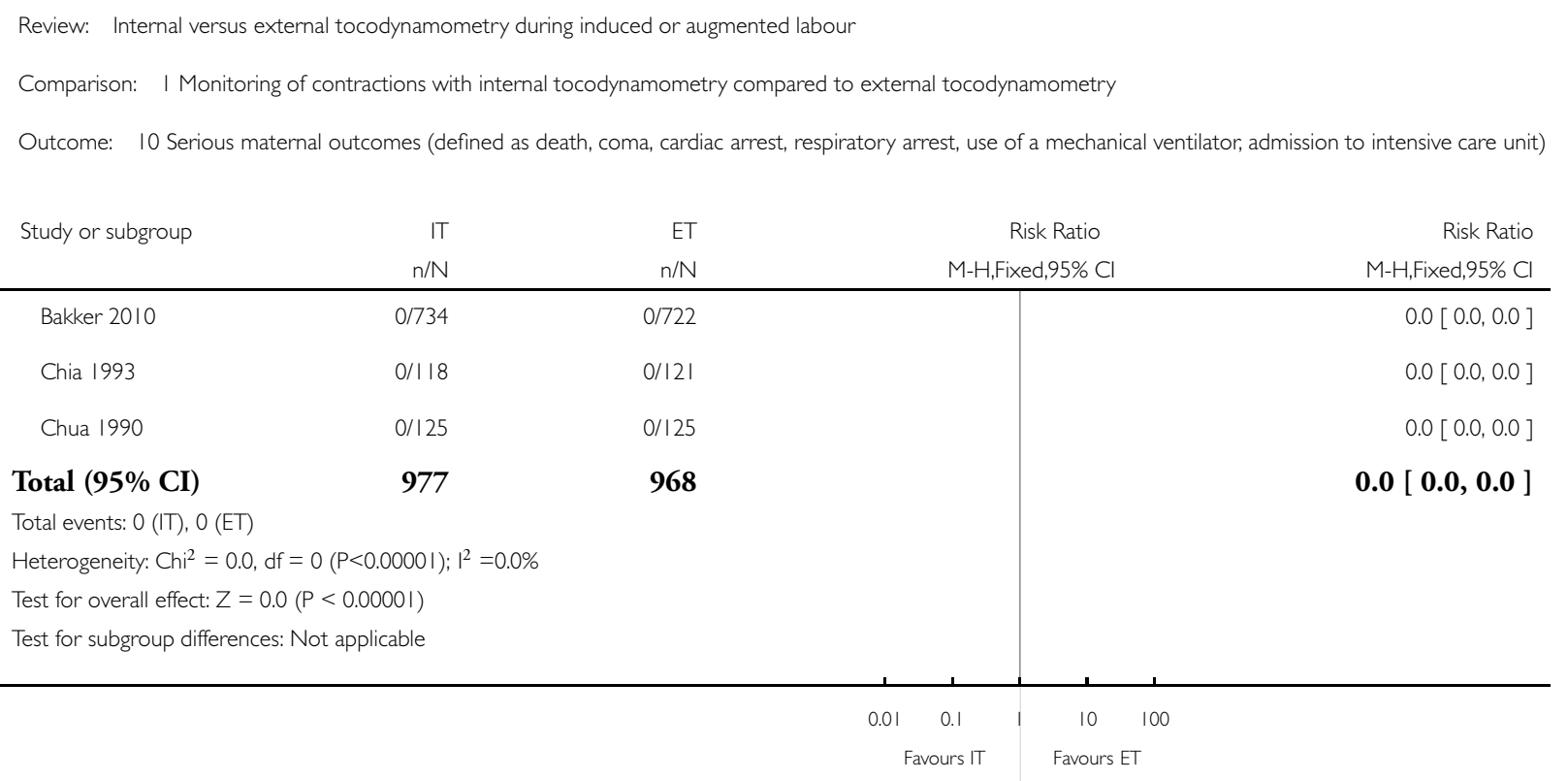


Analysis I.I I. Comparison I Monitoring of contractions with internal tocodynamometry compared to external tocodynamometry, Outcome I I Instrumental delivery.

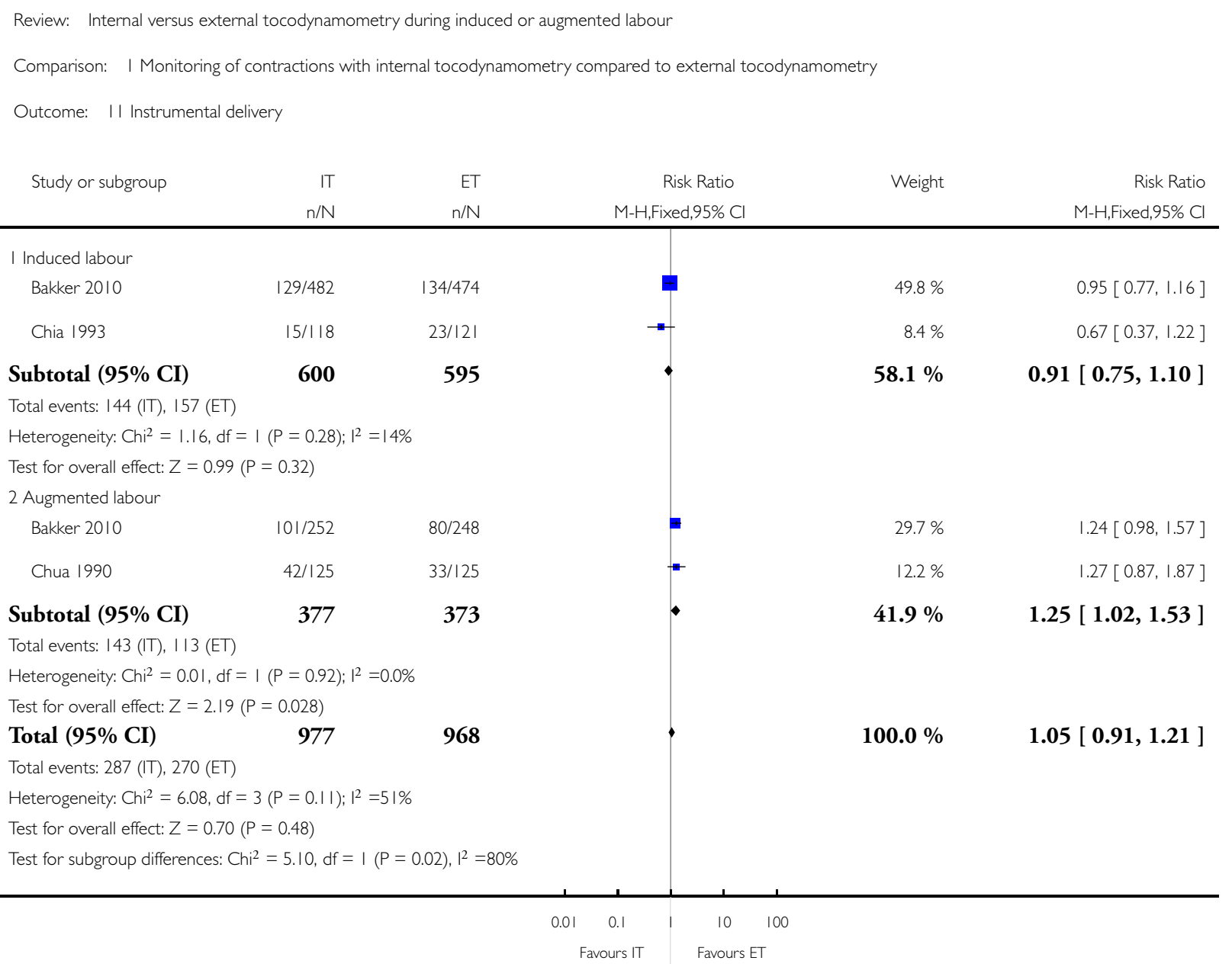


Analysis I.I2. Comparison I Monitoring of contractions with internal tocodynamometry compared to external tocodynamometry, Outcome 12 Instrumental vaginal delivery.

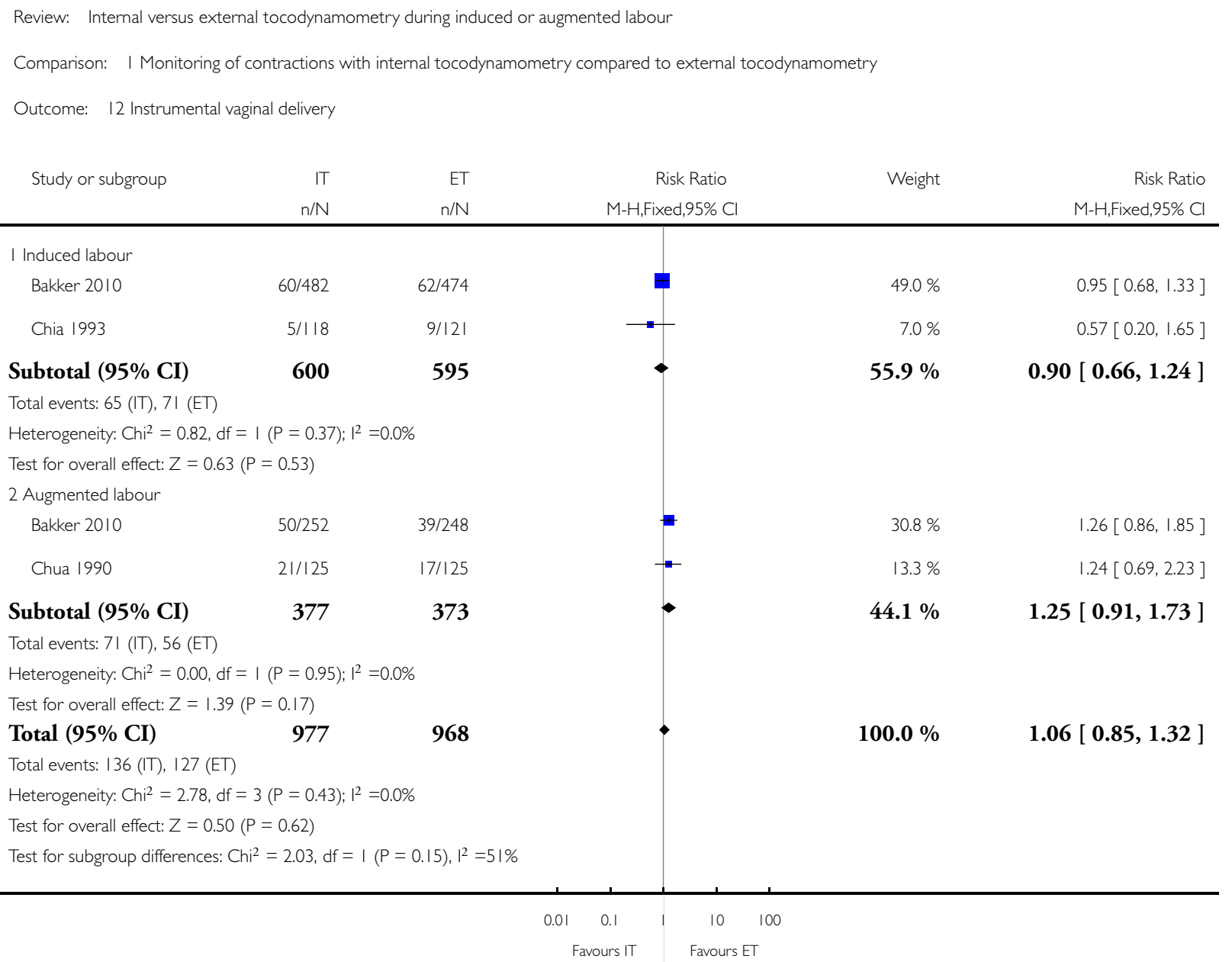


Analysis I.I3. Comparison I Monitoring of contractions with internal tocodynamometry compared to external tocodynamometry, Outcome 13 Caesarean section.

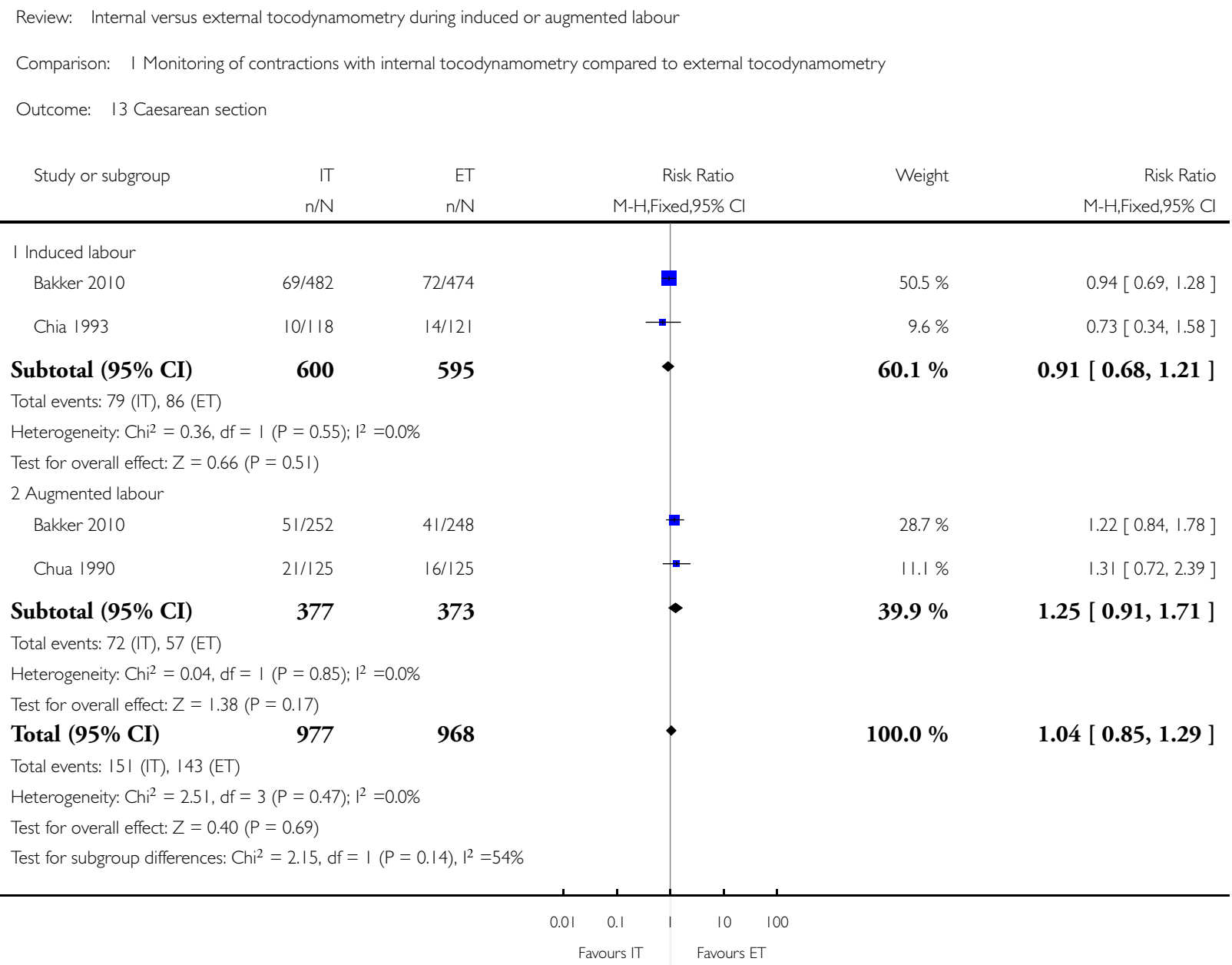


Analysis I.I4. Comparison I Monitoring of contractions with internal tocodynamometry compared to external tocodynamometry, Outcome 14 Mean time to delivery.

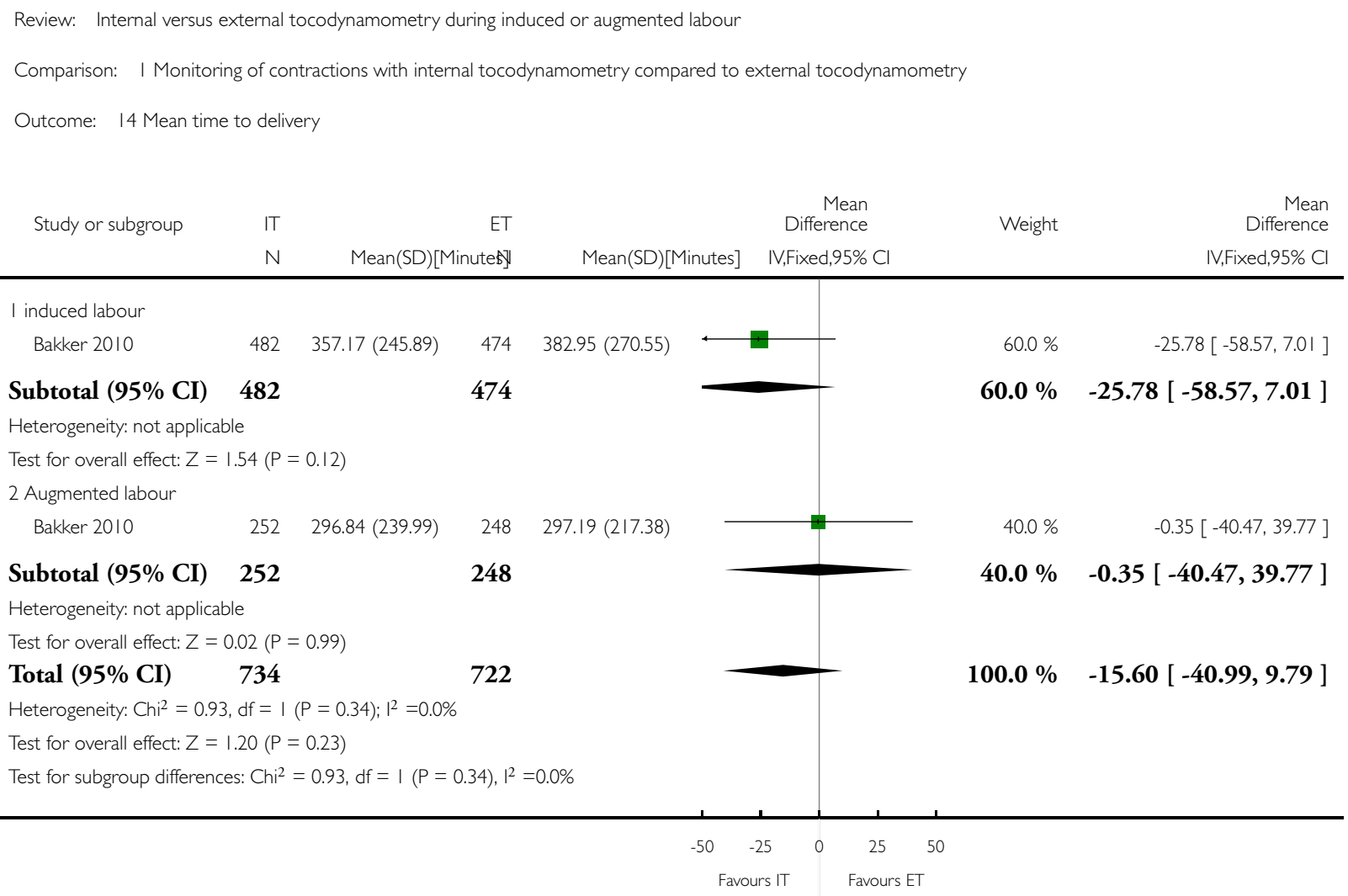


Analysis I.I5. Comparison I Monitoring of contractions with internal tocodynamometry compared to external tocodynamometry, Outcome 15 Placental or fetal vessel damage.

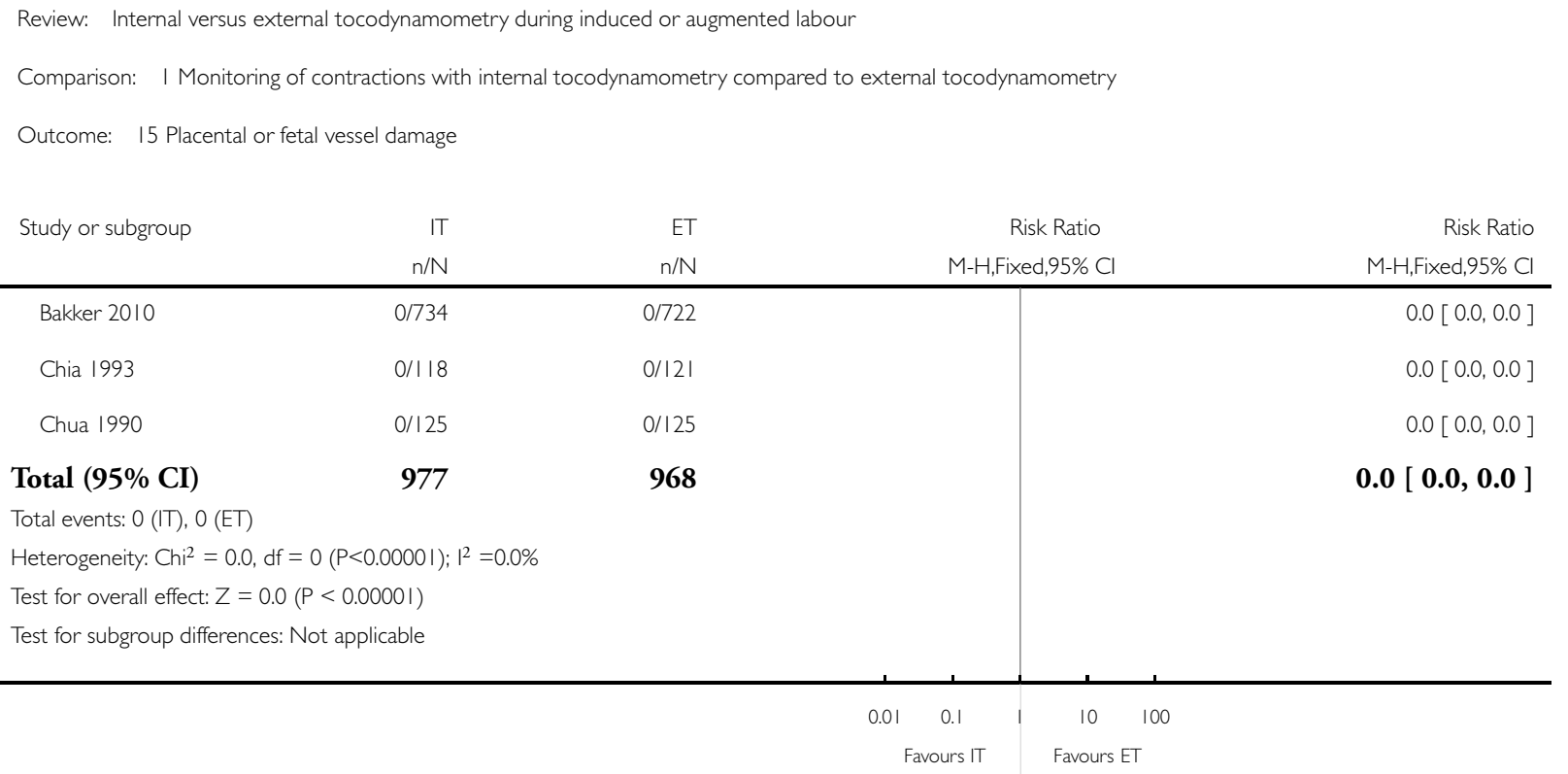

Analysis I.16. Comparison I Monitoring of contractions with internal tocodynamometry compared to external tocodynamometry, Outcome 16 Indication of infection up to three weeks postpartum in mother or child.

Review: Internal versus external tocodynamometry during induced or augmented labour

Comparison: I Monitoring of contractions with internal tocodynamometry compared to external tocodynamometry

Outcome: 16 Indication of infection up to three weeks postpartum in mother or child

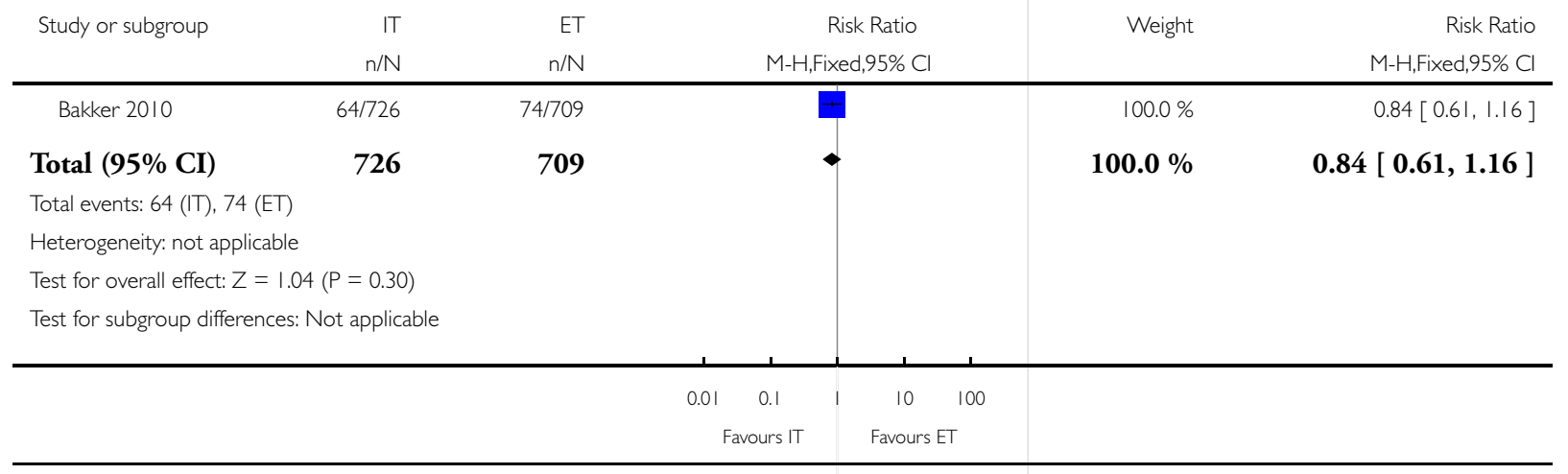

Internal versus external tocodynamometry during induced or augmented labour (Review)

Copyright $\odot 2012$ The Cochrane Collaboration. Published by John Wiley \& Sons, Ltd. 
Analysis I.I7. Comparison I Monitoring of contractions with internal tocodynamometry compared to external tocodynamometry, Outcome 17 Signs intrauterine infection during labor.

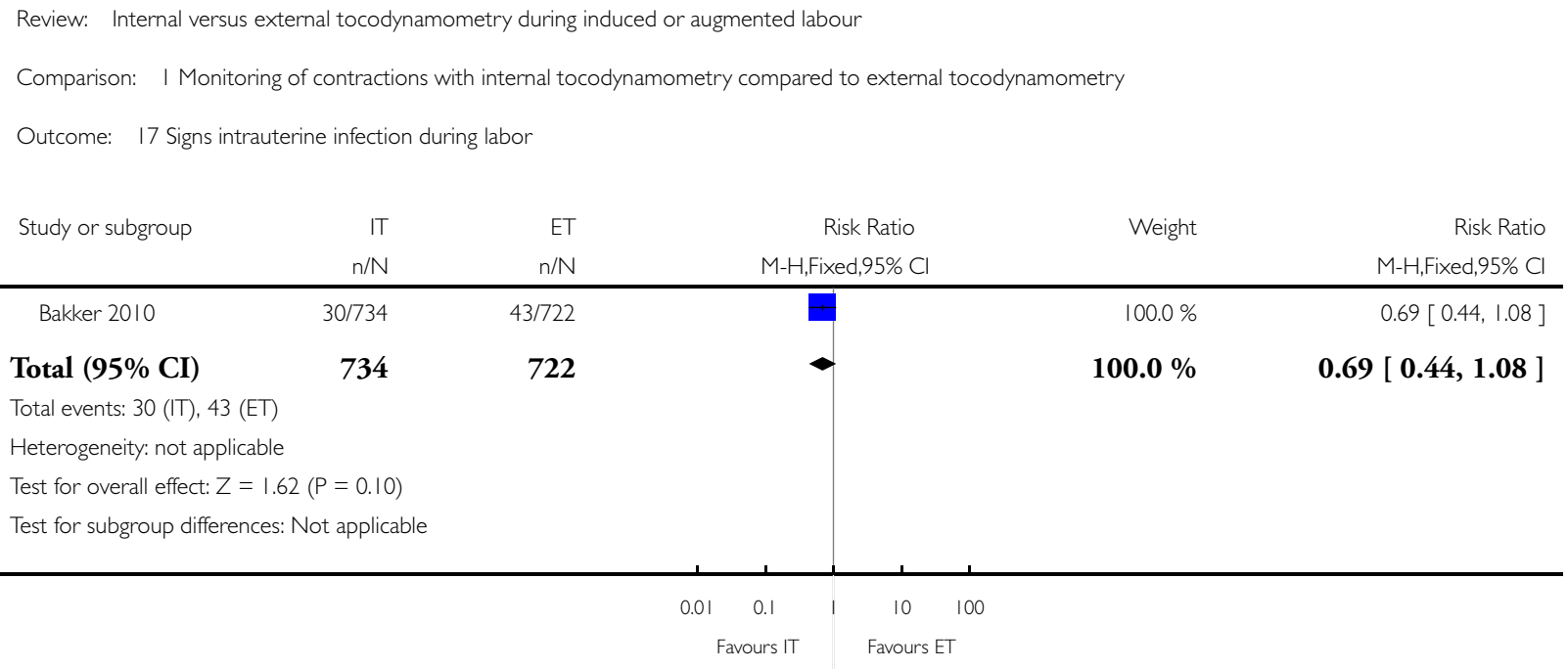

\section{ADDITIONAL TABLES}

Table 1. Median time to delivery

\begin{tabular}{|c|c|c|c|c|c|c|}
\hline Outcome & $\begin{array}{l}\text { No of partici- } \\
\text { pants (studies) }\end{array}$ & $\begin{array}{l}\text { External toco- } \\
\text { dynamometry }\end{array}$ & $\begin{array}{l}\text { Internal toco- } \\
\text { dynamometry }\end{array}$ & $\mathbf{R R}$ & CI & P value \\
\hline $\begin{array}{l}\text { Time to deliv- } \\
\text { ery after induc- } \\
\text { tion (minutes } \pm \\
\text { SD) }\end{array}$ & $\begin{array}{l}1195 \\
\text { (2 studies) }\end{array}$ & $\begin{array}{l}358 \pm 247(\mathrm{n}= \\
474) \\
363 \pm 212(\mathrm{n}= \\
121)\end{array}$ & $\begin{array}{l}313 \pm 299(\mathrm{n}= \\
482) \\
337 \pm 180(\mathrm{n}= \\
118)\end{array}$ & & & ns \\
\hline $\begin{array}{l}\text { Time to delivery } \\
\text { after augmenta- } \\
\text { tion } \\
\text { (minutes } \pm \text { SD) }\end{array}$ & $\begin{array}{l}750 \\
\text { (2 studies) }\end{array}$ & $\begin{array}{l}386 \pm 280(\mathrm{n}= \\
248) \\
273 \pm 228(\mathrm{n}= \\
125)\end{array}$ & $\begin{array}{l}299 \pm 239(\mathrm{n}= \\
252) \\
269 \pm 158(125)\end{array}$ & & & \\
\hline
\end{tabular}


Time to delivery is presented as median time in minutes

$\mathrm{SD}=$ standard deviation

\section{A P P E N D I CES}

\section{Appendix I. PubMed search}

Authors searched PubMed (1966 to 7 March 2012)

"uterine monitoring"[MeSH Terms] OR tocography[Text Word]

Limits Activated: Humans, Female

Hits 189

We selected on title and abstract, 6 relevant articles remained

\section{H I S T O R Y}

Protocol first published: Issue 1, 2008

Review first published: Issue 12, 2012

\begin{tabular}{lll}
\hline Date & Event & Description \\
\hline 29 January 2009 & Amended & Contact details edited. \\
\hline 11 November 2008 & Amended & Converted to new review format. \\
\hline
\end{tabular}

\section{CONTRIBUTIONSOFAUTHORS}

Designing the protocol: Jannet Bakker and Petra Janssen co-wrote the original protocol. Ben Willem Mol, Joris van der Post and Dimitri Papatsonis worked collaboratively in the development of the protocol and gave feedback on the draft of the review. Jannet Bakker and Petra Janssen performed the search of the literature and assessed the included studies. Jannet Bakker and Karlijn van Halem wrote the review. Birgit van der Goes assessed the Bakker trial for inclusion, risk of bias table and data extraction. 


\section{DECLARATIONSOF INTEREST}

As the contact person for this review is also the first author of the largest study (Bakker 2010) that was included, the decision for inclusion and assessment of the Bakker trial for inclusion, risk of bias and data extraction was done by Birgit van de Goes who was not involved in the Bakker trial in any way.

All authors declared no individual conflict of interest.

\section{SOURCES OF SUPPORT}

\section{Internal sources}

- No support, Not specified.

\section{External sources}

- No support, Not specified.

\section{DIFFERENCES BETWEEN PROTOCOLANDREVIEW}

In addition to the search of the Pregnancy and Childbirth Group Trials Register, we also searched PubMed - this was not pre-specified in our protocol.

\section{NDEX TERMS}

\section{Medical Subject Headings (MeSH)}

Injections, Intravenous; Labor, Induced [* ${ }^{*}$ ethods]; Oxytocics [*administration \& dosage]; Oxytocin [ ${ }^{*}$ administration \& dosage]; Randomized Controlled Trials as Topic; Uterine Contraction [ ${ }^{*}$ physiology]; Uterine Monitoring [instrumentation; ${ }^{*}$ methods]

\section{MeSH check words}

Female; Humans; Pregnancy 